NBER WORKING PAPER SERIES

\author{
THE EFFECTS OF HUMAN \\ RESOURCE MANAGEMENT PRACTICES \\ ON PRODUCTIVITY
}

Casey Ichniowski

Kathryn Shaw

Giovanna Prennushi

Working Paper 5333

\author{
NATIONAL BUREAU OF ECONOMIC RESEARCH \\ 1050 Massachusetts Avenue \\ Cambridge, MA 02138 \\ November 1995
}

The authors gratefully acknowledge helpful comments from Robert Gibbons, Zvi Griliches, Daniel Hamermesh, James Heckman, Bengt Holmstrom, Paul Milgrom, and John Roberts, and from the participants in seminars at: the National Bureau of Economic Research, Cornell University, M.I.T., Harvard University, University of Michigan, University of Maryland, Columbia University, Ohio State University, Carnegie-Mellon University, the Bureau of Labor Statistics, the Federal Reserve Board, and the American Economics Association meetings. The authors also acknowledge the generous financial support of the Alfred P. Sloan Foundation and the Columbia University Center for Japanese Economy and Business and the research assistance of Linda Christie. This paper is part of NBER's research programs in Labor Studies and Productivity. Any opinions expressed are those of the authors and not those of the National Bureau of Economic Research.

() 1995 by Casey Ichniowski, Kathryn Shaw and Giovanna Prennushi. All rights reserved. Short sections of text, not to exceed two paragraphs, may be quoted without explicit permission provided that full credit, including $\odot$ notice, is given to the source. 


\section{THE EFFECTS OF HUMAN \\ RESOURCE MANAGEMENT PRACTICES \\ ON PRODUCTIVITY}

\section{ABSTRACT}

Increasingly, firms are considering the adoption of new work practices, such as problemsolving teams, enhanced communication with workers, employment security, flexibility in job assignments, training workers for multiple jobs, and greater reliance on incentive pay. This paper provides empirical evidence to address the question: do these human resource management practices improve worker productivity?

For this study, we constructed our own data base through personal site visits to 26 steel plants which contained one specific steelmaking process, and collected longitudinal data with precise measures on productivity, work practices, and the technology in these production lines. The empirical results consistently support the following conclusion: the adoption of a coherent system of these new work practices, including work teams, flexible job assignments, employment security, training in multiple jobs, and extensive reliance on incentive pay, produces substantially higher levels of productivity than do more "traditional" approaches involving narrow job definitions, strict work rules, and hourly pay with close supervision. In contrast, adopting individual work practice innovations in isolation has no effect on productivity. We interpret this evidence as support for recent theoretical models which stress the importance of complementarities among a firm's work practices.

Casey Ichniowski

Uris Hall 713

Columbia University

New York, NY 10027

and NBER
Kathryn Shaw

G.S.I.A.

Carnegie-Mellon University

Pittsburgh, PA 15213

and NBER
Giovanna Prennushi

G.S.I.A.

Carnegie-Mellon University

Pittsburgh, PA 15213 
A firm's choice of employment practices can determine the productivity of its workers according to a large body of theoretical research in economics. Theories addressing productivity effects of work practices often focus on ways in which compensation policies, such as profit sharing, efficiency wage payments, or other forms of incentive pay, can affect workers' productivity. ${ }^{1}$ Other models examine the effects of a different set of employment practices, including the use of work teams, careful employee selection, sharing of financial information, employee voice mechanisms, and employment security policies. ${ }^{2}$ Still other theories suggest that clusters of related work practices may be more important determinants of productivity than are individual work practices. ${ }^{3}$ The number of theoretical models addressing the roles of employment practices has mushroomed over the last fifteen years, yet in sharp contrast, there exists little convincing empirical evidence examining the actual productivity effects of alternative employment practices. ${ }^{4}$

This study addresses this gap in the literature by assembling a new data set and developing empirical models specifically aimed at producing convincing estimates of productivity effects of different employment practices. Our empirical approach has several distinctive features. First, we gather data that is restricted to one very specific type of finishing line in the steel industry. The narrow focus of this data set eliminates many sources of heterogeneity that confound productivity comparisons in more aggregate data and in more heterogeneous samples. Second, we develop a detailed model of this particular production

\footnotetext{
'On these topics, see, for example, Weitzman (1980), Shapiro and Stiglitz (1984), Lazear (1986), and Lazear and Rosen (1981). For recent reviews, see Lazear (1991, 1992).

${ }^{2}$ For example, see (in the order of the listed topics): Holmstrom (1982), Alchian and Demsetz (1972), McAfee and McMillan (1991); Waldman (1984), Weiss (1980); Farrell and Gibbons (1991), Hart (1983); Freeman (1980); and Aoki (1988).

${ }^{3}$ See especially, Holmstrom and Milgrom (1994) and Milgrom and Roberts (1990, 1993).

${ }^{4}$ There are some exceptions however, particularly with regard to empirical studies of the effects of profit sharing (see Weitzman and Kruse (1990) for a review) and the effects of incentive pay plans for executives (see Jensen and Murphy (1990) and their references)
} 
process based on observations made during visits to each work site. We estimate the productivity model using precise measures of productivity, capital equipment, employment practices, and other line-specific determinants of productivity that we collected from each work site. Third, we obtain longitudinal data on each production line to estimate fixed effects models that investigate changes in productivity within production lines due to changes in their employment practices.

Two primary results consistently emerge from the empirical models. First, certain forms of incentive wage contracts and related employment practices raise the performance of production workers, relative to their performance under the more traditional employment practices of fixed hourly pay and extensive monitoring by foremen. Second, clusters of employment policies, which we also refer to as systems of human resource management (HRM) practices, have large effects on productivity, while marginal changes in individual work practices have little or no effect on productivity. We interpret these results as support for recent theories which stress the importance of complementarities among a firm's employment practices (Milgrom and Roberts, 1990, 1993; Holmstrom and Milgrom, 1994).

The next section reviews theories which predict that clusters of practices will have bigger effects on a firm's productivity than will individual practices due to complementarities among a firm's work practices. Section II describes the sample and data and develops the productivity model to be estimated. Section III presents data on the distribution of HRM practices and on the combinations of HRM practices observed in the sample. Section IV presents estimates of the effects of HRM practices on productivity, while section $\mathrm{V}$ identifies costs which appear to limit the adoption of productivity-enhancing work practices.

\section{THEORIES OF COMPLEMENTARITIES AMONG HRM PRACTICES}

Incentive contract theory addresses the issue of how to motivate employees to work hard when their performance cannot be perfectly measured or monitored. This literature 
identifies a number of considerations that complicate the design of optimal employment practices. For example, in many work settings, the output of an entire production unit may be easier to measure than is the output of an individual worker, but tying incentive pay to measures of group output can lead to free-rider problems. In addition, firms may need to develop effective incentives for valuable, yet difficult-to-measure, aspects of employee performance, such as employee initiative or cooperation. Finally, firms may need to elicit worker ideas for improving productivity when workers possess valuable knowledge that management does not have.

Recent theoretical work on incentive contracts suggests that sets of complementary HRM practices will be effective in addressing the kinds of issues that firms often confront when designing their employment practices. If complementarities among HRM practices are important, then introducing clusters of related work practices will have larger effects on productivity than will changes in individual HRM practices. We consider several alternative theoretical studies that argue that these kinds of complementarities among HRM practices are important considerations in a firm's choice of its work practices.

\section{Complementary Practices to Overcome Free Riding}

In many firms, incentives can only be paid to groups of workers, as in bonuses to shifts of workers or profit sharing to entire firms. The use of group rather than individual incentives might be due to the inability to observe individual output or to a production function in which the output from team effort is greater than the sum of individual output. When group output is the basis for pay decisions, free riders are a problem. Kandel and Lazear (1992) show that group incentives can stimulate performance if group incentives are 
coupled with several other HRM practices that address the free-rider problem.

In particular, firms can overcome free-rider problems by developing a "norm" or "culture" of high effort among employees. The norm can be maintained through peer pressure from those employees who feel a sense of guilt or shame for not working up to the norm. Kandel and Lazear (1992, pp. 814-5) show that, when workers differ according to a personality trait of whether or not they respond to shame, the different types of workers will not self-sort. Therefore, to be most effective, group incentive pay should be coupled with careful selection procedures. Moreover, firms should make "up-front expenditures ... [to] create loyalty and team spirit" to develop the culture of high effort among workers. Finally, after the initial selection and orientation of workers, practices like quality circles and work teams may be just as important for their cultural effects on team spirit and for the opportunities they create for workers to monitor each other as they are for the specific work tasks that take place in teams (Kandel and Lazear, 1992, pp. 807-8).

Thus, Kandel and Lazear (1992) identify a set of HRM practices that enhance the effectiveness of group incentive contracts; careful employee selection, indoctrination and orientation at the time of entry, team-oriented work groups, and other opportunities for workers and managers to meet. We refer to these as HRM practices with cultural complementarities, because these practices develop a "culture of high effort" and an "environment of positive peer pressure" that facilitates mutual monitoring among workers and makes group incentive pay more effective.

\section{Complementary Practices to Make Subjective Appraisals of Workers Effective}

In addition to free-rider problems, another difficulty with incentive pay schemes is that 
they are often based on readily available, but incomplete, performance measures, such as the quantity of output. Incorporating other valued dimensions of performance in the incentive contract will enhance its effectiveness. However, in many cases, important dimensions of employee performance include factors like the workers' dependability, cooperation, or problem-solving initiative, factors which require subjective assessments by managers.

Baker, Gibbons and Murphy (1994) demonstrate that "subjective incentive contracts" which reward employees for hard-to-measure factors can be complements with accurate objective incentive pay plans. The principal reason for the complementarity between subjective performance evaluations and objective bonus plans in their model is that the effectiveness of subjective appraisals depends critically on whether workers trust management to assess subjective dimensions of performance honestly, and effective objective incentives should increase this labor-management trust. In particular, an accurate objective bonus plan increases expected profits, which in turn increases both the value of the future employment relationship and management's concern for maintaining its reputation for assessing subjective aspects of worker performance honestly. Therefore, accurate objective incentive pay plans are complementary with subjective incentive pay plans because the combination provides an incentive for the firm to maintain a reputation for following through on commitments. ${ }^{5}$

\footnotetext{
s Baker, Gibbons and Murphy (1994) also show that the two types of incentive instruments may be substitutes under certain conditions -- specifically, when the objective measure of performance becomes close to a perfect measure. A principal reason for this result is that their model only allows for unidimensional worker effort, so that when one instrument becomes particularly good, the marginal value of using the other instrument for eliciting the same behavior declines. Holmstrom and Milgrom (1994) consider a less restrictive model in which workers perform multiple tasks and show that in this context two different incentive instruments aimed at eliciting different worker tasks will be complements under a broader set of conditions. The fundamental reason for the complementarity in the multi-task model is that "increasing the incentive for just one task could cause a worker to devote too much effort to that one task while neglecting other [valued] aspects of the job." (Holmstrom and Milgrom, 1994, 973) From our field investigations, we expect that the two types of incentive devices will be complementary because of the issue of labor-management trust raised by Baker, Gibbons and Murphy and because different instruments can
} 
There are many other HRM practices like subjective incentive contracts that expect workers to expend effort in return for uncertain expected future rewards. For example, workers will only expend extra effort to make team problem-solving meetings successful if they expect that the increased firm value will be reflected in higher future pay or in a lower probability of future layoffs.

HRM practices, such as teamwork, cooperation in problem-solving initiatives, and pay plans that require subjective evaluations, should therefore be complements with objective payfor-performance plans, because the objective pay plans raise the firm's profitability and thus the value of its reputation. We refer to these as trust-based complementarities among HRM practices. Furthermore, HRM practices, like careful screening, early indoctrination and orientation, and regular team meetings which according to Kandel and Lazear (1992) help make objective group incentive pay schemes more effective, should in turn be complements with subjective performance appraisals and team problem-solving initiatives, because the former practices will increase the value of the firm and make pledges about future payments more credible to employees.

\section{Complementary Practices to Elicit Workers' Ideas}

In many manufacturing firms, employees possess detailed knowledge about the production process that management does not have. Worker ideas for improving productivity can therefore be a particularly valuable form of employee participation. However, workers' ideas for improving productivity may result in the elimination of jobs. An employment security policy is therefore likely to be a necessary complement to employee participation in

elicit different valued behaviors as in Holmstrom and Milgrom. 
problem-solving teams or in other productivity improvement programs. Aoki (1988) argues that this combination of employment security and employee participation in problem-solving activities is an important part of the implicit contract between workers and management in large Japanese firms.

Milgrom and Roberts $(1990,1993)$ also show that a firm is likely to implement other complementary HRM policies once it makes a job security pledge. A commitment to longerterm employment relations makes flexibility in job assignments more valuable: firms that have promised to avoid layoffs can instead respond to demand shocks by reassigning workers to those jobs that are most valuable after the changes in demand. Flexibility in job assignments in turn requires more training. Training workers in multiple skills should also make the employment security pledge more credible (Carmichael and MacLeod, 1993). Lower probabilities of exit from the firm may also raise the value of communications and voice mechanisms (Hirschman, 1979). Milgrom and Roberts (1993) argue that the package of policies including employment security, problem-solving teams, job flexibility, training for multiple jobs, and employee communication mechanisms found often in large Japanese manufacturing firms provides a good example of what they term technical complementarities among HRM policies.

\section{Empirical Hypotheses}

These studies all develop different theoretical rationales for the same conclusion: HRM policies are complementary. Based on these theories, the primary hypothesis to be tested in the empirical analysis is that combinations of HRM practices have bigger effects on productivity than do the sum of component effects due to individual pnactices. In short, 
interaction effects among sets of HRM policies are important determinants of productivity. ${ }^{6}$

Firms benefit little from making "marginal" decisions about one HRM practice at a time, but instead realize the largest productivity increases by making discrete jumps in the use of clusters of practices.

The theoretical studies also identify complementarities among specific HRM policies that suggest a second testable hypothesis. These studies imply that a combination of practices spanning seven HRM policy areas -- extensive screening and selection; teamwork and team meetings; compensation based on objective incentive plans and subjective dimensions of performance; employment security; flexible job assignment; skills training; and communication procedures -- will produce the highest levels of productivity, because these policies help overcome free-rider problems, make employers' pledges to evaluate subjective dimensions of performance credible, and elicit employees' productivity-improving ideas. Combining practices in these seven HRM policy areas into a coherent HRM system will increase productivity by more than the sum of the effects of individual practices.

\section{SAMPLE, DATA, AND ECONOMETRIC SPECIFICATION}

\section{Sample Design}

The sample for this study is from the steel industry. In designing this sample, we sought to minimize the heterogeneity in production processes and outputs that often limit the

\footnotetext{
${ }^{6}$ The traditional economic concept of complementarity typically requires nonnegative mixed partial derivatives. However, firms' objective functions are not likely to be twice differentiable with respect to discontinuous "inputs" like HRM policies. Milgrom and Roberts (1993) and Holmstrom and Milgrom (1994) propose the use of supermodularity in objective functions to extend the concept of complementarity to discontinuous inputs like organizational policies. If a firm's production function is supermodular with respect to two HRM policies, then interaction effects among HRM policies will be significant. With supermodularity, the sum of (a) the productivity increase from adopting the first policy in isolation and (b) the productivity increase from adopting the second policy in isolation will be less than the productivity increase from the simultaneous adoption of both HRM policies.
} 
persuasiveness of empirical studies that make firm-level or plant-level performance comparisons. Observations in the sample are not steel companies, divisions of steel companies, or even steel mills. Rather, the sample consists of observations on a very specific type of steel finishing process. This study's econometric analysis uses a panel data set of up to 2190 monthly observations on the productivity of steel finishing lines.

Of the approximately 60 finishing lines of this type in the United States, we personally visited 45 lines owned by 21 companies at locations ranging from New York to Alabama to California. We conducted field interviews for one to three days at each site. Through these visits and follow-up phone calls, we collected four types of data: information on HRM practices; information on production processes; data on the performance of the finishing lines and the values of the inputs; and wage data. Four of the 45 lines could not provide performance data because they had been operating for only a few months. Of the remaining 41 lines, the sample for the econometric analysis below is from 36 lines that provided comparable monthly productivity data. The sample includes multiple lines for major steel producers as well as lines for smaller companies that operate only one or two lines. The sample contains unionized lines as well as nonunion lines. According to company and industry sources, the sample includes high and low performers, and, as the results below will indicate, it also includes a very wide range of HRM environments.

\section{$\underline{\text { HRM Variables }}$}

We gathered HRM data by conducting standardized, but open-ended, interviews with HR managers, labor relations managers, operations managers of the finishing lines, superintendents, line workers, and union representatives in organized lines. We collected 
supporting information from personnel files, personnel manuals, collective bargaining agreements, and other primary source documents. Using this detailed information on the HRM practices at each site, we coded responses to a set of specific survey-type questions about the HRM practices. From these questions and responses, we constructed a detailed set of HRM dummy variables. Table 1 provides the definitions of a subset of representative HRM variables and their mean values for the panel data set. These variables measure practices in each of the seven HRM policy areas which the theories reviewed in Section I suggest will be important -- recruiting and selection, incentive compensation, team-based work organization, flexible job assignment, employment security, training, and communication procedures. ${ }^{7} \mathrm{We}$ also include two traditional labor relations indicators that are not themselves employment practices: the union status of the line and a grievance rate variable. ${ }^{8}$

\section{Specification of the Dependent Productivity Variable and the Production Function}

The individual and combined effects of the HRM variables on productivity are the focus of the paper. To develop convincing models of the productivity of these lines, we toured each line with an experienced engineer, area operations manager, or superintendent.

\footnotetext{
${ }^{7}$ Virtually all lines have some kind of incentive pay. The LINE INCENTIVE variable differentiates between the older traditional incentives in the steel industry which reward individual shifts of workers for lineal feet of steel produced (LINE INCENTIVE $=0$ ) and the newer incentive plans that apply to the line as a whole and base incentives on multiple dimensions of output including quality and quantity of production (LINE INCENTIVE $=1$ ).

${ }^{8}$ In our sample, managers typically could only provide historical records on the number of grievances filed for their entire mill, but not for the production line we are studying. However, at all lines, those interviewed were able to identify time periods when the number of grievances filed by workers on the production line averaged more or less than one per month (LOW GRIEVANCE = 1). While grievance rate variables in previous research (e.g., Ichniowski, 1986) are typically measures like grievances filed per worker, we do not divide grievances by manning levels because crew sizes and manning levels are virtually identical across the production lines. Finally, we also define the LOW GRIEVANCE and MEET UNION variables for the nonunion lines in our sample. Based on our field interviews, we assigned the nonunion lines a value of one for both of these variables. Complaints through formal grievance machinery or informal complaint procedures at these lines were consistently low, and managers met regularly with workers or work team representatives.
} 
HRM Variable Name

1. Incentive Pay

a. PROFIT SHARING

b. LINE INCENTIVES

2. Recruiting and Selection

a. HIGH RECRUIT

3. Work Teams

a. HIGII PARTICIPATION

b. MULTIPLE TEAMS

c. FORMAL TEAMS

4. Employment Security

a.EMPLOYMENT SECURITY

5. Flexible Job Assignment

a. JOB ROTATION

6. Skills Training

a. HIGH TRAIN

b. LOW TRAIN

7. Communication

a. INFO

b. MEET WORKERS

c. MEET UNION

TABLE 1

Definitions of HRM Variables

$\underline{\text { Mean }}^{2} \quad$ Dummy Variable Description

.700

.085
Is there a company profit-sharing plan covering the line workers?

Are operators covered by a "non-traditional" incentive pay plan which applies across shifts of workers and which is sensitive to quality as well as quantity aspects of output?

Was an extensive selection procedure used to hire new workers including tests for personality traits needed for cooperative team environments and efforts to set clear expectations about required work behaviors of the new workers?

Are a majority of operators involved in formal or informal work teams or other related problem-solving activities?

Do operators participate in more than one problem-solving team?

Are operators organized into formal work teams either on the line or for the purposes of problem-solving activities according to an established policy with at least some operators involved in team activities?

Has the company committed to a goal of long-term employment security and offered employees a pledge of employment security?

Do operators rotate across jobs or tasks on the line?

Have all operators on the line received off-the-job training?

Have at least some operators received off-the-job training?

Are operators and union representatives, if any, provided with financial information on a regular basis?

Do line managers meet off-line with operators to discuss issues of concern including issues related to performance and quality?

Do operators or union representatives and managers meet often to discuss concerns and cooperate in finding solutions to issues? 
TABLE 1 (continued)

Definitions of HRM Variables

\section{Labor Relations}
a. UNION
.917
Is the line a unionized operation?
b. LOW GRIEVANCE
.499 Is the grievance filing rate less than twelve per year?

Note to Table 1: (a) Means reported in column 2 refer to the means for the main sample of $n=2190$ line-months used in the productivity models reported in Tables 4,5 , and 6 . For the MEET UNION and LOW GRIEVANCE variables, we assign nonunion lines a value of 1 for these two dummy variables because of regular meetings with worker representatives and low levels of complaints in their formal or informal complaint or grievance procedures. The means of these two variables among the sample of union observations are .153 and .453 respectively. 
These tours gave us a detailed understanding of the finishing line production process and an opportunity to discuss the best ways to measure and compare the performance outcomes of different finishing lines. We then collected data on relevant performance measures and on equipment features and line specifications that affect the performance measures.

The basic production process is very similar in all lines. Steel input on each line is a roll, or coil, of flat-rolled steel weighing about twelve tons. The coil is loaded at the beginning of the line where the steel strip is welded to the end of the previous coil on the line. The coil is then unrolled so that a long continuous sheet of steel threads its way through the machinery that treats the steel. After the finishing treatment, the steel strip is then recoiled and cut at the exit end of the process. The line can operate continuously around the clock as coils are welded to one another.

The productivity model that we develop to describe this production process is best understood within the context of an "engineering production function." The tonnage that comes off the line per month $(\mathrm{Q})$ is a function of the tonnage loaded onto the line (and thus the width (w) and thickness or gauge (g) of the steel strip), the speed of the line (s), and the hours it is running (h). If $h^{\text {s }}$ represents the maximum hours the line is scheduled to run, then the potential steel output on line $i$ in month $t$ is arithmetically determined by the four key technical parameters $\left(\mathrm{w}, \mathrm{g}, \mathrm{s}\right.$, and $\left.\mathrm{h}^{\mathrm{s}}\right)$ according to:

(1) Potential $Q_{i t}=\gamma\left(w_{i t}^{*} g_{i t}^{*} s_{i t}^{*} h_{i t}^{s}\right)$ where the quantity in parentheses in (1) is the volume of steel through line $i$ in month $t$, and $\gamma$ is an estimate of the density of steel.

Since the production parameters in (1) are determined by the technical specifications 
of the line's equipment and the specifications of the input coil regarding coil width and gauge, a line's production in any month depends only on the number of hours the line actually runs:

$$
\text { Actual } Q_{i t}=\left[\gamma\left(w_{i t}^{*} g_{i t}^{*} s_{i t}^{*} h^{3}\right)\right]\left(1-d_{i t}\right)
$$

where $d_{i t}$ is delays -- the fraction of total scheduled hours which are lost due to unscheduled line stops. Once the technological parameters and product mix are specified, production depends solely on delays. Productivity improves by increasing uptime, $\left(1-d_{i}\right)$.

Because uptime directly determines tons of steel output and because uptime figures are especially comparable across companies, we estimate the following equation directly:

$$
\left(1-d_{i t}\right)=f\left(V_{i t}, C A P_{i t}, I_{i t}, M N T_{i t}, H R M_{i t}\right)+e_{i t}
$$

The dependent uptime variable in equation (3), 1- $\mathrm{d}_{\mathrm{it}}$, measures the percent of scheduled operating time that the line actually runs. It has a mean of .919 and a standard deviation of .044 in the sample of 2190 "line-month" observations that is used in most of the empirical analyses. It ranges from a low of .398 to a high of .996.

The HRM vector in equation (3) is a vector of variables developed from the dummy variables in Table 1 to represent the HRM environment (as will be described below).

Concerning the other control variables in equation (3), finishing lines with older capital stocks should tend to have more equipment failures: vector VN measures the year the line started operations and the current age of the line in period $t$. In addition to these measures of vintage, we also include a dummy variable indicating whether the line is in the first twelve months of operations and a 1-to-12 time counter for the first twelve months of operations. Managers on the lines we visited, including some lines just beginning operations, attested to the high levels of delays in this startup period. 
CAP includes up to nine dummy variables to indicate the presence of specific features of the equipment along the line that could complicate the production process, making delays more likely, or streamlining operations and thereby reducing delays. CAP also includes a variable for periods when new equipment was being installed on a line, since these periods tend to have relatively high levels of delays, and includes a dummy for the degree of computer automation of the line. IQ is an index of the quality of the steel input. Lower quality steel input tends to cause more line delays, according to those interviewed. Finally, some lines may have low levels of unscheduled delays simply because they schedule more downtime for maintenance work. We therefore include the variable MNT in equation (3) which measures the number of annual eight-hour maintenance shifts at the line. Different levels of detail in the specification of these control variables will be used in the estimation to test the sensitivity of the empirical patterns to these specification differences.

We first estimate the uptime productivity equation by ordinary least squares under the assumption of i.i.d. error terms with zero mean:

$$
\left(1-d_{i t}\right)=\beta^{\prime} X_{i t}+\gamma^{\prime} H R M_{i t}+e_{i t}
$$

where $\mathrm{X}_{\mathrm{it}}$ contains the control variables listed in equation (3). We also allow for the possibility that $e_{i t}$ contains unexplained cross-section variation that is correlated with variables in $\mathrm{X}_{\mathrm{ih}}$, and so we reestimate the model with controls for fixed plant-specific effects: ${ }^{9}$

$$
\left(1-d_{i t}\right)=\alpha_{i}+\beta^{\prime} X_{i t}+\gamma^{\prime} H R M_{i t}+\varepsilon_{i t}
$$

\footnotetext{
${ }^{9}$ Equation (4) could also be estimated as a random effects model. However, this specification assumes that the error term is uncorrelated with the right-hand-side variables, or $E\left(x_{i t}, \alpha_{i}\right)=0$. To test this assumption, define $Z$ as the matrix of the differences of the variables from their cross-sectional means (i.e., the fixed effects matrix) and estimate the OLS regression $\left(1-d_{i t}\right)=b^{\prime} X_{i t}+g^{\prime} Z_{i t}+u_{i t}$. For the Table 4 column 1-8 specifications below, F-tests reject the hypothesis that $\mathrm{g}^{\prime}=0$ in these models (e.g., $F[9,2152]=12.83$ for the column 5 model), thus rejecting the random effects' assumption that $\mathrm{E}\left(\mathrm{X}_{\mathrm{it},}, \alpha_{\mathrm{i}}\right)=0$.
} 
where the $\alpha_{i}^{\prime}$ s are separate intercepts for each production line. Finally, given the panel nature of the sample, we also reestimate equations (4) and (5) with a correction for first-order serial correlation in the residuals. ${ }^{10}$

\section{EMPIRICAL RESULTS: CORRELATIONS AMONG HRM PRACTICES AND MEASURING HRM SYSTEMS}

Section I reviews theories which argue that complementarities among HRM practices will be important. Table 2 presents simple correlations among the fifteen HRM variables listed in Table 1 and provides the first evidence of the existence of complementarities among HRM practices. The sample for this correlation matrix consists of one observation for every distinct HRM environment experienced by a line during the period for which the line supplied productivity data. For example, a line that has not changed its HRM policies during its data period will be represented by one observation. A line that has changed HRM practices at a given point in time will be represented by two different HRM environment observations. For the 36 lines in our sample, there are 54 distinct HRM environments.

Even for this small sample of distinct HRM environments, a large number of significant positive correlations are observed. 57 out of 105 of the simple correlations shown in Table 2 are significant. Furthermore, the patterns in these correlations reflect precisely the kinds of complementarities among HRM policies that are suggested by the theories reviewed in Section I. First, as suggested by Kandel and Lazear (1992), newer group incentive pay

\footnotetext{
${ }^{10}$ The dependent variable, percent uptime, is bounded by zero and one, suggesting the possibility of Tobit estimation. In the empirical results in Section IV below, we focus on the results from the fixed effects estimation. We do not pursue Tobit estimation for the fixed effects models in Section IV, because coefficient estimates of fixed effects Tobit models are not consistent: the non-linearity of the Tobit model introduces an incidental parameters problem. However, when the equation (4) OLS model is estimated as a Tobit with a mass point at one, the estimated coefficients are essentially the same as the OLS estimates that are presented in Section IV below. A double-sided Tobit model, with a second mass point at zero, is not necessary since no lines have uptimes near zero.
} 
TABLE 2

Correlations Among HRM Practices

Incentive Pay

PROFIT INCENT

1. PROF SHARE

$1.0 \quad .111$

RECRT

$\underline{\text { HITM }}$

FTEAM

MTEAM SECUR

2. LINE INC.

1.0

$.088 \quad-.031$

.116

.052

$.299 * *$

Selection

3. HI RECRUIT

1.0

$.436 * * * \quad .000$

$.229 *$

$.384 * * *$

Teams

4. HIGH TEAMS

1.0

$.324 * * *$

$.526 * * *$

.031

5.FRML.TEAMS

1.0

$.477^{* * *} \quad .194$

6. MULTITEAM

1.0

$-.152$

Emp. Security

7. SECUR.POL.

Job Flexibility

8. ROTATE

Skills \&

Knowledge

9. HI TRAIN

10. LOW TRAIN

Communications

11. INFOSHAR

12.MEETWRKR

13.MEETUNION

Labor Relations

14. UNION

15. LOGRIEV

Notes to Table 2:

*** .- significant at .01 -level

** -- significant at .05-level

* -. significant at .10-level 
TABLE 2 (continued)

\section{Correlations Among HRM Practices}

\begin{tabular}{|c|c|c|c|c|c|c|c|}
\hline ROTAT & HITRN & LOTRN & INFO & MEETW & MEETU & UNION & LOGRV \\
\hline-.166 & .084 & -.031 & $.427^{* * *}$ & .049 & .021 & -.060 & -.089 \\
\hline $.372 * * *$ & $.302^{* *}$ & $412 * * *$ & .041 & $.325^{* *}$ & $.265^{*}$ & -.140 & .184 \\
\hline $.397^{* * *}$ & .208 & $436 * * *$ & $.283^{* *}$ & $.226^{*}$ & $.529 * * *$ & -.460 & $.272^{* *}$ \\
\hline $.492 * * *$ & $.578 * * *$ & $.645^{* * *}$ & $.243 *$ & $.434^{* * *}$ & $.434 * * *$ & $-.281^{* *}$ & $.301 * *$ \\
\hline .192 & $.506^{* * *}$ & $.487^{* * *}$ & .185 & $.418^{* * *}$ & .178 & .141 & .222 \\
\hline .177 & $.706 * * *$ & $.630^{* * *}$ & .191 & .087 & $.319^{* *}$ & .135 & $.268 * *$ \\
\hline .032 & -.084 & -.053 & $.659 * * *$ & $.429 * * *$ & $.352^{* * *}$ & $-.384^{* * *}$ & -.144 \\
\hline \multirow[t]{3}{*}{1.0} & $.473^{* * *}$ & $.352^{* * *}$ & .064 & $.255^{*}$ & .137 & .090 & $.308 * *$ \\
\hline & 1.0 & $.779 * * *$ & -.046 & .121 & .172 & .033 & $.303^{* *}$ \\
\hline & & 1.0 & .000 & .185 & $.336 * *$ & $-.281^{* *}$ & $.463^{* * *}$ \\
\hline & & & 1.0 & $.418^{* * *}$ & $.356^{* * *}$ & .141 & -.222 \\
\hline & & & & 1.0 & $.244^{*}$ & -.081 & -.008 \\
\hline & & & & & 1.0 & $-.529 * * *$ & $.515^{* * *}$ \\
\hline & & & & & & 1.0 & $\begin{array}{l}-.272^{* *} \\
1.0\end{array}$ \\
\hline
\end{tabular}

Notes to Table 2 (continued):

$N=54$ observations with one observation for each distinct HRM environment experienced by a line. The number of observations on different HRM environments per finishing line ranges from one to three. For the MEET UNION and LOW GRIEVANCE variables, we assign nonunion lines a value of 1 for these two dummy variables because of regular meetings with worker representatives and low levels of complaints in their formal or informal complaint or grievance procedures. 
plans (LINE INCENTIVE in line 2) are positively correlated with extensive recruiting (HIGH RECRUIT), with team-based work structures (FORMAL TEAMS, and MULTIPLE TEAMS), and with labor-management meetings (MEET WORKERS and MEET UNION). These practices should help to screen out workers who would not participate in team-based work environments, to reenforce team spirit, and to provide opportunities for monitoring. ${ }^{11}$ Second, these newer objective pay plans are also positively correlated with the level of worker involvement in teams (HIGH TEAMS) and with other HRM practices suggested by the theoretical arguments of Baker, Gibbons, and Murphy (1994). ${ }^{12}$ Finally, Table 2 also shows significant positive correlations among employment security (SECURITY POLICY), intensity of screening (HIGH RECRUIT), labor-management communication (INFO SHARE, MEET WORKERS, MEET UNION), and certain measures of job flexibility, ${ }^{13}$ as Milgrom and Roberts (1990, 1993) argue.

\section{Measuring HRM Systems}

The high degree of intercorrelation among HRM practices shown in Table 2 indicates

\footnotetext{
"Interestingly, the same kinds of complementarities are not associated with company profit-sharing plans. In large steel companies, these plans cover diverse workers at many different work sites. Company profitability is affected by the activities of all these workers, as well as by factors outside the control of employees. Kandel and Lazear (1992) argue that company profit sharing in these kinds of settings will likely be undermined by free-rider effects regardless of any attempts to instill peer pressure. In any case, lines covered by profit-sharing plans are not more likely than other lines to have intensive recruiting, team-based work organization, regular meetings with workers or other related HRM practices. Of the fourteen other variables considered in Table 2, profit sharing has a positive significant correlation only with sharing financial information - a policy that would be needed in order to calculate payments under the profit sharing plan -- and with the employment security variable.

12 While not displayed in Table 2, a few production lines have instituted "pay-for-knowledge" incentives. Assessing employee knowledge involves a high degree of subjectivity. Pay-for-knowledge plans have only been instituted where the newer line incentive pay plans are in effect -- another possible indication of the complementarity between subjective worker evaluations and effective objective incentive pay plans.

${ }^{13}$ While the employment security variable is not strongly correlated with the job rotation variable, employment security is strongly correlated with a variable measuring combined job classifications for operators. Furthermore, those lines with job rotation or combined job classifications are also more likely to provide training to their workers.
} 
that empirical models which estimate the impact of any one individual HRM practice on productivity will yield biased coefficients due to the omission of other HRM practices with which the one included practice is correlated. One possible solution to this omitted variable bias would be to enter the entire set of potentially important HRM variables into the productivity equations. However, this approach is confounded by the severe collinearity among the HRM practices, making any one coefficient uninterpretable, ${ }^{14}$ and would not directly test whether combinations of HRM practices are the critical determinants of productivity.

To test the importance of sets of highly correlated, and presumably complementary, HRM practices, the effects of interactions among the practices must be examined. There are an insufficient number of degrees of freedom to test a full set of interaction terms among all available HRM practice variables. An expansive set of interaction terms would also still be confounded by collinearity among practices. In this section, we pursue four alternative approaches for identifying a more parsimonious set of distinctive HRM practice combinations that empirically are the most common.

\section{Method 1: Classification According to Theoretically Important HRM Practices}

In the first approach, we examine variables which describe the seven HRM policy areas -- extensive recruiting and indoctrination, subjective and objective incentive compensation plans, teamwork, training, job flexibility, labor-management communication, and employment security -- which the theoretical discussion of Section I identifies as

\footnotetext{
${ }^{14}$ Examining collinearity diagnostics developed by Belsley, Kuh and Welsch (1980) for a regression that includes all fifteen HRM variables listed in Table 2 reveals a clear case of what Belsley, Kuh, and Welsh term "competing collinearity".
} 
important. We use a somewhat larger set of HRM variables than is listed in Table 1 to provide as rich a description of the overall HRM environment as possible, using from one to six specific practices describing each of the seven HRM policy areas. ${ }^{15}$ Examination of these detailed HRM variables reveals four very distinctive groups of HRM practices as described in Table 3.

The theoretical discussion of Section I suggests that productivity will be highest when the lines have a set of innovative practices that incorporate new work practices in all seven HRM policy areas. ${ }^{16}$ One set of steel lines does this. Managers of these lines spent well over a year carefully selecting, orienting, and training new employees before employees began work on the line. All employees are trained in technical line operations, statistical process control, and team problem-solving techniques, and are involved in multiple problem-solving teams. Workers are trained to do all jobs on the line and regularly rotate across tasks.

\footnotetext{
${ }^{13}$ In addition to the fifteen HRM variables listed in Table 1, we also consider a dummy variable to capture intermediate levels of recruiting and screening activities. We include dummies to measure training in team problem solving techniques and in statistical process control methods. In the area of work teams, we include a variable for the use of informal work teams assembled on an "as needed" basis and one that measures whether the local union supports or resists team activities. Also in the area of participation, we include a variable to measure whether employees have input into the development and updating of standard work practices. We add another incentive pay variable for the presence of multi-attribute gain-sharing plans, and a dummy for skill-based salary pay plans for operators. In the area of job flexibility, we add two variables to measure combined operator job classifications and combined maintenance worker job classifications. Finally, because we are interested in classifying lines according to their work policies and practices, we did not include the union status dummy or the grievance rate variable. In all, twenty-six HRM policy variables are used in the four classification procedures.

${ }^{16}$ The conclusion that the most productive system of HRM practices should have innovative practices in all seven HRM areas is due to the fact that the different theories reviewed in Section I consider overlapping sets of HRM practices. In particular, Baker, Murphy, and Gibbons (1994) combine subjective performance practices (such as performance appraisals or problem solving teams) with objective incentive pay in their optimal system; Kandel and Lazear (1992) combine objective group incentive pay with careful screening, indoctrination, training, and teamwork; and Milgrom and Roberts (1993) combine job security with teamwork, job flexibility, training, and communication. These theories do not argue that every pair of HRM policies in these seven areas is complementary. Rather, the overlap among the policies considered in the different theories implies that the most productive HRM system will have innovative work practices in all HRM areas.
} 
TABLE 3

\section{PERCENTAGE OF PRODUCTION LINES WITH SPECIFIC HRM PRACTICES WITHIN FOUR HRM SYSTEM CATEGORIES}

PRACTICES IN SEVEN HRM POLICY AREAS

1. Incentive Pay

a. Multi-Attribute Line Incentives

1.00

.31

.00

2. Recruiting

a. Very Extensive Screening

3. Teanwork

a. High \% In Prob. Solv. Teams

1.00

.85

.10

.00

b. Workers in Multiple Teams

1.00

1.00

.62

.00

1.00

1.00

.00

c. Some Teamwork Practice

4. Employment Security

a. Employ. Security Pledge

5. Job Flexibility

a. Job Rotation

6. Training

a. Off-Site Train, All Workers

1.00

1.00

.69

.00

.00

b. Off-Site Train, Some Workers

7. Labor-Management

Communication

a. Information Sharing

1.00

1.00

b. Regular Meetings with .54 .62 .00 .77 .72 .00 Workers

\section{Note to Table 3:}

a -- The sample $(\mathrm{N}=54)$ is the same as in Table 2. It includes one observation for each HRM environment experienced by a line. 
Employee pay is based on a multi-attribute gain-sharing plan or a "pay-for-knowledge" system in which employees' salaries increase as they progress through a series of knowledge and skill banks. Finally, workers enjoy an implicit employment security pledge and regular contact among workers, union officials, and the relatively few managers on the line. We refer to these lines as the lines having HRM System 1. Column 1 of Table 3 reports means of the HRM variables for this group of lines.

At the other extreme, another set of lines has none of these innovative practices. These facilities probably match the popular view of work practices in the steel industry: strict work rules and narrow job responsibilities; incentive pay based on quantity and not quality of output; no work teams; no practice of managers sharing financial information or meeting regularly off-line with workers or their union representatives; no screening; training only from "what you pick up on the job;" and close supervision by a relatively large number of foremen. We refer to these lines as the lines with HRM System 4 . Column 4 of Table 3 reports means of the HRM variables for this group of lines.

A third group of lines has a set of HRM practices similar to those that comprise the traditional HRM System 4 except for differences in two, and only two, HRM policy areas. Lines classified as HRM System 3 have made some attempt to initiate worker involvement in teams, but none of these lines has a high level of involvement either in terms of the number of workers who participate or in terms of the number of problem-solving teams any given worker joins. The limited effort at worker involvement in teams at these lines is always coupled with some labor-management communication practices, either sharing of financial information or regular meetings between line managers and workers or their union 
representatives. Column 3 of Table 3 reports means of the HRM variables for lines in HRM System 3.

The last set of lines, those in HRM System 2, is distinct from those in the previous three systems. Unlike lines with HRM System 3, lines in HRM System 2 have both high levels of worker involvement in teams and extensive training. In this group, either a majority of workers participate in problem-solving teams, or some workers participate in multiple teams, and workers receive regular training in problem-solving skills and production skills. At the same time, these lines lack one or more of the following practices which define HRM System 1 -- extensive screening, job rotation or reduced job classifications, multi-attribute gain-sharing, or employment security. ${ }^{17}$ Column 2 of Table 3 reports means of the HRM variables for lines in HRM System 2.

Table 3 clearly illustrates the distinctive features of each group's HRM environment. ${ }^{18}$ The "traditional" System 4 has none of these HRM practices. System 3 has some teams with low levels of involvement, some labor-management communication, and very little else.

System 2 lines typically have much higher levels of worker involvement in teams, extensive worker training, and some "progressive" HRM practice in one or two other HRM policy areas. System 1 lines are very distinctive as the only lines with extensive policies in all seven areas.

\footnotetext{
${ }^{17}$ A small number of lines have either high participation in teams or extensive training, but not both policies together. To categorize these lines according to their overall HRM environments, we classify these lines into HRM System 2 or 3 depending on how extensive the HRM practices in the other policy areas are. The empirical results below are virtually unaffected by how these few "intermediate" cases are categorized into HRM System 2 or 3.

18 The sample for Table 3 is the same as the one used for the Table 2 correlations containing one observation for each distinct HRM environment experienced by a line.
} 


\section{Method 2: 0-to-7 HRM Index}

The second classification procedure examines the same set of HRM practices considered in method 1. Within each of the seven HRM policy areas, we create a dummy for whether the line ranks "high" or "low" in that policy area. ${ }^{19}$ These seven dummy variables are summed into a 0-to-7 HRM index. Based on this index, we break the lines into four groups: HRM index $=0 ;$ HRM index $=1-2 ; \mathrm{HRM}$ index $=3-6 ; \mathrm{HRM}$ index $=7$.

\section{Methods 3 and 4: Classification Based on Nominate and Guttman Scaling Scores}

Finally, we use two multivariate classification procedures, Nominate scaling and Guttman scaling, to categorize the HRM environments of the finishing lines. These procedures assume that one or more underlying dimensions are responsible for generating the individual HRM practices at a line, so that the lines can be ranked according to the underlying dimension or dimensions. In the case of our finishing lines, the underlying dimension might be the extent to which lines have introduced "progressive" HRM practices that are intended to elicit valuable, yet hard-to-observe, cooperative behaviors from workers. At one end of the underlying scale will be finishing lines with cooperative labor-management relations and multiple innovative HRM policies, while at the other end of the scale will be finishing lines with adversarial labor relations and an uncooperative work force.

In implementing these two classification procedures, we allow the procedures to categorize the lines according to the same detailed set of HRM policy variables considered in

\footnotetext{
${ }^{19}$ High rankings in the seven policy areas are determined by: extensive screening and orientation at time of hire; line incentives sensitive to quality and quantity of production; training in team problem-solving skills together with either a majority of workers participating in teams or at least some workers in several problem-solving teams; extensive skills training; two or more communication practices including information sharing, regular meetings with workers off-line, or regular meetings with union representatives in union lines; job rotation or reduced job classifications; and employment security.
} 
the other methods. Based on the HRM score that each line receives along the principal dimension identified by these procedures, we partition the lines into four groups by looking for natural break points in the score. ${ }^{20}$

All four classification procedures produce very similar groupings of the lines. In the empirical work in the next section, we focus on the productivity effects of the four systems identified by the first method, but we also present estimates using the other three classification procedures to assess the robustness of the results with respect to the classification procedures.

\section{EMPIRICAL RESULTS: PRODUCTIVITY EFFECTS OF HRM SYSTEMS}

Table 4 presents estimates of the effects of the HRM System variables on the productivity of the finishing lines. Columns 1-4 report OLS estimates of uptime equation (4), with the HRM Systems defined according to the four alternative classification methods described above, and with a basic set of technology controls. Columns 5-8 replicate the models in columns 1-4, but add a more detailed set of controls for specific pieces of capital equipment. Finally, column 9 reports estimates from the equation (5) fixed effects model ${ }^{21}$ of

\footnotetext{
${ }^{20}$ For the problem of a single underlying dimension, let the position of the $i$-th finishing line be given by $x_{i}$, and the position of $j$-th HRM policy be given by two points, $z_{j k}$, where $k=y, n$ represents adoption ( $y$ ) or no adoption (n). In the Nominate procedure, the probability of adopting policy $\mathrm{j}$ is determined by its profitability which is assumed to be: $\pi\left(z_{i j k}\right)=\beta \exp \left[-\left(d_{i j k}\right)^{2} / 8\right]+\varepsilon_{i j k}$, where $d_{i j k}$ is the Euclidean distance between $x_{i}$ and $z_{j y}$ or $z_{j n}$. Nominate uses an iterative procedure to estimate $\beta, x_{i}$, and $z_{j k}$. For a detailed description of Nominate, see Poole and Rosenthal $(1985 ; 1991)$. For a description of Guttman scaling, see Ghisellli, Campbell, and Zedeck (1981). In our analysis, we examine the scores for each finishing line, for example, the $x_{i}$ 's in Nominate which range from -1 to $\mathrm{I}$, and partition the lines into four categories based on natural break points in the procedures' scores.

${ }^{21}$ Because the first three methods listed in Table 4 identify precisely the same lines as the ones which "switch HRM systems," the fixed effects estimates of the HRM systems variables are the same under all three of these classification procedures. The identification of "HRM system switchers" is somewhat different according to the categories defined by the 0 -to-7 HRM index. The fixed effects estimates under this classification method are still quite similar to those produced under the other three methods. These estimates are presented in note $d$ to Table 4 .
} 
TABLE 4

Estimated Productivity Effects of HRM Systems

[Dependent Variable: Uptime; $\mathrm{N}=2190$ ]

HRM System

1. HRM System 1

2. HRM System 2

3. HRM System 3

$\mathrm{R}^{2}$

OLS Models Without Detailed Machinery Controls" (columns 1 - 4)

Classified
According
to HRM
Practices

(1)

$.087 * * *$

$(.007)$

Classified
According
to Nominate
Score

(.004)

$.008 * * *$
$(.002)$

.272
(2)

$.104 * * *$

(.007)

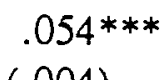

Classified According to Guttman Score

$.096 * * *$
$(.006)$

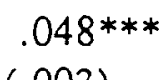

(.003) $.025 * * *$ (.003) .299

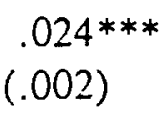

.306
Classified According to 0-7 HRM Index $.063 * * *$ (.006) $.011^{* * *}$ $(.003)$ $.004 * *$ (.002) .242

Notes to Table 4:

$* * *$.- significant at .01 -level
$* *$.- significant at .05 -level
$*$.- significant at .10 -level

a -- Control variables in columns 1-4 are: number of years line has been operating and years squared; year line was built and year built squared; dummy for startup periods indicated by first twelve months of operations and 1-to-12 time trend for month of startup operation; 1-to-5 index of quality of steel input; number of annual 8 -hour scheduled maintenance shifis.

b - Control variables in columns 5-8 are: all controls listed in note a; dumny for type of customer; maximum speed of line and speed squared; maximum width of the line and width squared; nine dummies to indicate specific pieces of equipment from start to finish of the line and a measure of the age of one piece of equipment at end of the line; a dummy to indicate high and low levels of computer control of line operations; and a variable to measure 6-month periods from the date that any new major pieces of equipment are introduced. 


\section{TABLE 4 (continued)}

Estimated Productivity Effects of HRM Systems

[Dependent Variable: Uptime; $\mathrm{N}=2190$ ]

\begin{tabular}{|c|c|c|c|c|}
\hline \multicolumn{4}{|c|}{ OLS Models With Detailed Machinery Controls ${ }^{\mathrm{b}}$} & $\frac{\text { Fixed Effects }}{\text { (column } 9)}$ \\
\hline Classified & Classified & Classified & Classified & Results \\
\hline According & According & According & According & For All \\
\hline to $\mathrm{HRM}$ & to Nominate & to Guttman & to $0.7 \mathrm{HRM}$ & Classification \\
\hline $\begin{array}{l}\text { Practices } \\
(5)\end{array}$ & $\begin{array}{c}\text { Score } \\
(6)\end{array}$ & $\begin{array}{c}\text { Score } \\
(7)\end{array}$ & $\begin{array}{c}\text { Index } \\
(8)\end{array}$ & $\begin{array}{l}\text { Procedures } \\
\text { (9) }\end{array}$ \\
\hline $\begin{array}{l}.067 * * * \\
(.007)\end{array}$ & $\begin{array}{l}.077^{* * *} \\
(.007)\end{array}$ & $\begin{array}{l}.076 * * * \\
(.007)\end{array}$ & $\begin{array}{l}.048^{* * *} \\
(.006)\end{array}$ & $\cdots$ \\
\hline $\begin{array}{l}.032 * * * \\
(.005)\end{array}$ & $\begin{array}{l}.041 * * * \\
(.005)\end{array}$ & $\begin{array}{l}.040 * * * \\
(.005)\end{array}$ & $\begin{array}{l}.014^{* * * *} \\
(.003)\end{array}$ & $\begin{array}{l}.035 * * * \\
(.008)\end{array}$ \\
\hline $\begin{array}{l}.014^{* * *} \\
(.003)\end{array}$ & $\begin{array}{l}.025^{* * *} \\
(.003)\end{array}$ & $\begin{array}{l}.021^{* * *} \\
(.004)\end{array}$ & $\begin{array}{l}.008 * * * \\
(.003)\end{array}$ & $\begin{array}{l}.025^{* * *} \\
(.006)\end{array}$ \\
\hline .409 & .419 & .412 & .403 & .463 \\
\hline
\end{tabular}

Notes to Table 4 (continued):

c -- Control variables in column 9 are: age of line and age squared: dummy for startup periods indicated by first twelve months of operations and 1-to-12 time trend for month of startup operation; $1-10-5$ index of quality of steel input; age of the end-of-the-line piece of equipment; a variable to measure 6 month periods from the date that any new major pieces of equipment are introduced; and estimated changes in the value of capital due 10 the introduction of any' new major pieces of machinery from the date the new equipment was installed.

d -. Coefficients on HRM Groups in the fixed effects models are identical under all classification procedures except for the 0-to-7 HRM index method, in which the coefficien and (standard error) for system 2 and system 3 are respectively: $.025(.005)$ and $.017(.005)$. There are no fixed effects estimates for the system 1 coefficient because no line switched into this group. 
the impact of the HRM Systems variables on line uptime. ${ }^{22}$

\section{Productivity Effects of Control Variables}

While the productivity effects of the HRM variables are the focus of this paper, the coefficients on the control variables have the expected signs and are statistically significant. The Table in Appendix A reports the full set of coefficients for the column 5, Table 4 model having the detailed set of control variables. As expected from our field investigations, the results show that lines have more delays with: less scheduled maintenance; lower quality steel input; older technologies; startup periods for brand new lines; the introduction of new pieces of equipment; and higher line speeds. ${ }^{23}$

\section{Productivity Effects of HRM System Dummy Variables}

The results of Table 4 show significant productivity effects of HRM Systems. In all eight OLS specifications, the four HRM systems from "least cooperative and innovative" to "very cooperative and innovative" also map out a clear hierarchy of productivity effects. In all eight specifications, F-tests reveal that HRM System 3 lines are significantly more productive than System 4 lines; HRM System 2 lines more productive than HRM System 3 lines; and very innovative HRM System 1 lines more productive than System 2 lines. The

\footnotetext{
${ }^{22}$ All nine models in Table 4 were also reestimated with corrections for first-order serial correlation. While each model shows evidence of serial correlation, the standard errors in models with this correction are only slightly larger than they are in the Table 4 models without the correction. The magnitudes of the coefficients are virtually unaffected by the correction for serial correlation and the coefficients on the HRM variables remain significant at well above the 01 -level.

23 We also examined the effects of other variables, such as measures of production worker and managerial quality and more complicated learning curve effects than are shown in the Table in Appendix A. Worker quality measures, such as tenure of the operations manager or production workers' average age, were always insignificant. Managers and production workers are remarkably homogeneous groups, so these measures do not reflect large differences in labor quality. We also found no evidence of more complicated learning curve effects, such as learning curve effects after the hiring of new managers or production workers or after other changes in line operations.
} 
difference in uptime going from the traditional HRM System 4 lines to the most innovative System 1 lines is about 7 percentage points according to the column 5-8 models which add detailed machinery controls to the specifications.

According to the fixed effects results (column 9), adopting more progressive HRM systems significantly improves productivity. Furthermore, the pattern of results in the column 9 fixed effects model is remarkably similar to the pattern in OLS results in columns 5-7. Even after controlling for other productivity-determining factors that changed over time within lines, ${ }^{24}$ a change from HRM System 4 to HRM Systems 3 or 2 increases line uptime by 2.5 and 3.5 percentage points, respectively. Note that no line implemented enough innovative HRM practices to move into the high productivity HRM System 1 group, thus there is no fixed effects coefficient for System $1 .^{25}$

The similarity of results between the column 9 fixed effects results and the OLS results in columns 5-8 with detailed capital controls is perhaps not surprising. The column 4 model includes a large set of dummy variables for equipment features, level of computerization of the line, and other detailed features that may control for any cross-line differences in productivity. The variation in productivity left to be explained after the inclusion of these controls in the column 5-8 models should be primarily the variation over time within lines.

\footnotetext{
${ }^{24}$ Coefficients on the control variables in the fixed effects models are generally significant in the expected directions. Startup periods have high levels of delay that tend to decrease as the startup period progresses. Periods when capital is introduced have significantly higher levels of delays. Increasing the quality of steel input over time within a line reduces delays. These coefficients are again consistent with evidence from our field interviews.

${ }^{25}$ The inability of lines to move into System 1 is very consistent with Milgrom and Roberts' (1993) theoretical arguments about HRM policy complementarities. To move into HRM System 1, a line would have to implement a very large number of new HRM policies. The lines in the HRM System 1 category are new production sites that carefully designed and implemented these new HRM policies at the time of startup.
} 


\section{The Productivity Effects of HRM Systems and Individual HRM Practices}

The results in Table 4 indicate that systems of HRM practices have significant productivity effects. Yet these results alone do not demonstrate complementarity among HRM practices. Data on the actual distribution of HRM practices in Tables 2 and 3 provide some evidence that HRM practices are complementary. Significant positive correlations exist among many HRM practices, and most innovative HRM practices can only be found in lines that have many other innovative HRM practices. Firms do implement HRM practices in a complementary fashion.

While the actual distribution of HRM practices shows that firms implement many practices in clusters, complementarity among HRM practices also requires that the magnitude of the productivity effect of a system of policies must be greater than the sum of the marginal effects due to the adoption of individual HRM practices that comprise the system. This section presents two additional tests on the issue of whether HRM practices are complementary inputs in a firm's production function.

In the first test, we include the dummies for individual HRM practices together with the HRM Systems variables in the uptime regression. Panel Al of Table 5 presents results from fifteen separate OLS models where each model includes a different individual HRM practice in addition to the HRM System dummy variables. The detailed set of control variables is included in each of these models. ${ }^{26}$

When the individual HRM practices are added to the uptime regressions, the

\footnotetext{
${ }^{26}$ As in Table 4, all OLS and fixed effects models in Table 5 were reestimated with corrections for first order serial correlation. Again, the magnitudes of all coefficients are virtually unaffected by this correction. Standard errors for some coefficients increase, but only slightly. The significance levels of all HRM coefficients are very similar in all cases to that shown in Table 5 .
} 
TABLE 5

Productivity Effects of HRM Systems and Individual Practices

[Dependent Variable: Uptime; $\mathrm{N}=2190$ ]

Panel A1: OLS WITH HRM SYSTEM VARIABLES ${ }^{\circ}$

\begin{tabular}{|c|c|c|c|c|c|c|c|}
\hline $\begin{array}{l}\text { 1a. HRM } \\
\text { System ! }\end{array}$ & $\begin{array}{l}.066^{* * *} \\
(.007)\end{array}$ & $\begin{array}{l}.068 * * \\
(.007)\end{array}$ & $\begin{array}{l}.068^{* * *} \\
(.015)\end{array}$ & $\begin{array}{l}.095 * * * \\
(.009)\end{array}$ & $\begin{array}{l}.062 * * * \\
(.008)\end{array}$ & $\begin{array}{l}.060^{* * *} \\
(.011)\end{array}$ & $\begin{array}{l}.047^{* * *} \\
(.010)\end{array}$ \\
\hline $\begin{array}{l}\text { b. HRM } \\
\text { System } 2\end{array}$ & $\begin{array}{l}.026^{* *} \\
(.005)\end{array}$ & $\begin{array}{l}.032 * * * \\
(.005)\end{array}$ & $\begin{array}{l}.032 * * * \\
(.005)\end{array}$ & $\begin{array}{l}.052^{* * *} \\
(.006)\end{array}$ & $\begin{array}{l}.027 * * * \\
(.006)\end{array}$ & $\begin{array}{l}.026 * * * \\
(.008)\end{array}$ & $\begin{array}{l}.023^{* * *} \\
(.005)\end{array}$ \\
\hline $\begin{array}{l}\text { c. HRM } \\
\text { System } 3\end{array}$ & $\begin{array}{l}.012^{* * *} \\
(.003)\end{array}$ & $\begin{array}{l}.014^{* * *} \\
(.003)\end{array}$ & $\begin{array}{l}.013 * * * \\
(.003)\end{array}$ & $\begin{array}{l}.019 * * * \\
(.004)\end{array}$ & $\begin{array}{l}.012^{* * *} \\
(.004)\end{array}$ & $\begin{array}{l}.014^{* * *} \\
(.003)\end{array}$ & $\begin{array}{l}.008^{* *} \\
(.004)\end{array}$ \\
\hline $\begin{array}{l}\text { HRM Policy } \\
\text { Included }\end{array}$ & PROFIT & INCENT & RECRT & HITEAM & FTEAMI & MTEAM & SECUR \\
\hline $\begin{array}{l}\text { 2. Coefficient } \\
\text { on HRM Pol. }\end{array}$ & $\begin{array}{l}.006 * * \\
(.003)\end{array}$ & $\begin{array}{l}-.002 \\
(.004)\end{array}$ & $\begin{array}{l}-.00 ! \\
(.00 !)\end{array}$ & $\begin{array}{l}-.023^{* * *} \\
(.004)\end{array}$ & $\begin{array}{l}.004 \\
(.003)\end{array}$ & $\begin{array}{c}.008 \\
(.009)\end{array}$ & $\begin{array}{l}.011 \\
(.004)\end{array}$ \\
\hline
\end{tabular}

Panel B1: FIXED EFFECTS WITH HRM SYSTEM VARIABLES ${ }^{c}$

\begin{tabular}{|c|c|c|c|c|c|c|c|}
\hline $\begin{array}{l}\text { 1a. HRM } \\
\text { System 1 }\end{array}$ & - & $\cdots$ & -- & $\cdots$ & -.- & $\cdots$ & -..- \\
\hline $\begin{array}{l}\text { b. HRM } \\
\text { System } 2\end{array}$ & -..- & $\begin{array}{l}.031^{* * *} \\
(.009)\end{array}$ & $\ldots$ & $\begin{array}{l}.058^{* * *} \\
(.010)\end{array}$ & $\begin{array}{l}.034^{* * *} \\
(.013)\end{array}$ & $\cdots$ & $\cdots$ \\
\hline $\begin{array}{l}\text { c. HRM } \\
\text { System } 3\end{array}$ & ...- & $\begin{array}{l}.023 * * * \\
(.006)\end{array}$ & --- & $\begin{array}{l}.028^{* * *} \\
(.006)\end{array}$ & $\begin{array}{l}.025 * * * \\
(.008)\end{array}$ & $\cdots$ & $\cdots$ \\
\hline $\begin{array}{l}\text { HRM Policy } \\
\text { Included }\end{array}$ & PROFIT & INCENT & RECRT & HITEAM & FTEAM & MTEAM & SECUR \\
\hline $\begin{array}{l}\text { 2. Coefficient } \\
\text { on HRM Pol. }\end{array}$ & $\cdots$ & $\begin{array}{l}.007 \\
(.005)\end{array}$ & $\ldots$ & $\begin{array}{l}-.024 * * * * \\
(.006)\end{array}$ & $\begin{array}{l}.001 \\
(.006)\end{array}$ & -.. & $-\cdots$ \\
\hline
\end{tabular}

Panel A2: OLS WITHOUT HRM SYSTEM VARIABLES ${ }^{\circ}$

\begin{tabular}{|c|c|c|c|c|c|c|c|}
\hline $\begin{array}{l}\text { HRM Policy } \\
\text { Included }\end{array}$ & PROFIT & INCENT & RECRT & HITEAM & FTEAM & MTEAM & SECUR \\
\hline $\begin{array}{l}\text { Coefficient } \\
\text { on HRM Pol. }\end{array}$ & $\begin{array}{l}.007^{* *} \\
(.002)\end{array}$ & $\begin{array}{l}.012^{* * *} \\
(.004)\end{array}$ & $\begin{array}{l}.029^{* * *} \\
(.004)\end{array}$ & $\begin{array}{l}.005^{*} \\
(.003)\end{array}$ & $\begin{array}{l}.014^{* * *} \\
(.003)\end{array}$ & $\begin{array}{l}.026^{* * *} \\
(.004)\end{array}$ & $\begin{array}{l}.025^{* * *} \\
(.003)\end{array}$ \\
\hline
\end{tabular}

Panel B2: FIXED EFFECTS WITHOUT HRM SYSTEM VARIABLES ${ }^{\circ}$

\begin{tabular}{|c|c|c|c|c|c|c|c|}
\hline $\begin{array}{l}\text { HRM Policy } \\
\text { Included }\end{array}$ & PROFIT & INCENT & RECRT & HITEAM & FTEAM & MTEAM & SECUR \\
\hline $\begin{array}{l}\text { Coefficient } \\
\text { on HRM Pol. }\end{array}$ & -... & $\begin{array}{l}.012 * * * \\
(.004)\end{array}$ & $\ldots$ & $\begin{array}{l}-.008^{*} \\
(.005)\end{array}$ & $\begin{array}{l}.011 * * * \\
(.004)\end{array}$ & $\begin{array}{l}.010^{*} \\
(.006)\end{array}$ & $\cdots$ \\
\hline
\end{tabular}




\section{TABLE 5 (continued)}

\section{Productivity Effects of HRM Systems and Individual Practices}

[Dependent Variable: Uptime; $N=2190]$

Panel A1: OLS WITH HRM SYSTEM VARIABLES

$\begin{array}{llllllll}.084 * * * & .068 * * * & .054 * * & .077 * * * & .060 * * * & .067 * * * & .073 * * * & .066 * * * \\ (.009) & (.008) & (.009) & (.011) & (.008) & (.010) & (.008) & (.008) \\ .033 * * * & .033 * * * & .021 * * * & .038 * * * & .028 * * * & .032 * * * & .037 * * * & .031 \cdots * \\ (.005) & (.006) & (.007) & (.007) & (.005) & (.006) & (.006) & (.005) \\ .018 * * * & .014 * * * & .013 * * * & .017 * * * & .012 * * * & .014 * * * & .016 * * * & .014 * * * \\ (.004) & (.003) & (.003) & (.004) & (.004) & (.004) & (.004) & (.004) \\ \text { ROTAT } & \text { HITRN } & \text { LOTRN } & \text { lNFO } & \text { MEETV } & \text { MIEETU } & \text { UNION } & \text { LOGRV } \\ & & & & & & & \\ -.021 * * * & -.003 & .013 * * & -.004 & .005 & .00003 & .012 & .0003 \\ (.006) & (.006) & (.006) & (.003) & (.004) & (.004) & (.008) & (.003)\end{array}$

Panel B1: FIXED EFFECTS WITH HRM SYSTEM VARIABLES ${ }^{c}$

\begin{tabular}{|c|c|c|c|c|c|c|c|}
\hline$\cdots$ & --- & $\ldots$ & $\cdots$ & $\cdots$ & -.-- & $\ldots$ & $-\cdot-$ \\
\hline -..- & $\begin{array}{l}.037^{* * *} \\
(.009)\end{array}$ & $\begin{array}{l}.028^{* * *} \\
(.010)\end{array}$ & $\cdots$ & $\begin{array}{l}.028 * * * \\
(.010)\end{array}$ & $\begin{array}{l}.031^{* * *} \\
(.009)\end{array}$ & ...- & $\begin{array}{l}.013 \\
(.013)\end{array}$ \\
\hline --.- & $\begin{array}{l}.025 * * * \\
(.006)\end{array}$ & $\begin{array}{l}.023 * * * \\
(.006)\end{array}$ & $\cdots$ & $\begin{array}{l}.024 * * * \\
(.006)\end{array}$ & $\begin{array}{l}.025^{* * *} \\
(.006)\end{array}$ & .... & $\begin{array}{l}.008 \\
(.010)\end{array}$ \\
\hline DTAT & HITRN & LOTRN & INFO & MEETW & MEETU & UNION & LOGRV \\
\hline .. & $\begin{array}{l}-.006 \\
(.007)\end{array}$ & $\begin{array}{c}.008 \\
(.006)\end{array}$ & .... & $\begin{array}{c}.007 \\
(.006)\end{array}$ & $\begin{array}{l}.014 \\
(.014)\end{array}$ & -... & $\begin{array}{l}.022 * * \\
(.010)\end{array}$ \\
\hline
\end{tabular}

Panel A2: OLS WITHOUT HRM SYSTEM VARIABLES ${ }^{\circ}$

ROTAT HITRN LOTRN INFO MEETW MEETU UNION LOGRV

$\begin{array}{llllllll}.010^{* *} & .016 & .026 * * * & .013^{* * *} & .021 * * * & .017^{* * *} & -.026 * * * & .012^{* * *} \\ (.005) & (.004) & .(.004) & (.002) & (.003) & (.003) & (.007) & (.003)\end{array}$

Panel B2: FIXED EFFECTS WITHOUT HRM SYSTEM VARIABLES ${ }^{c}$ ROTAT HITRN LOTRN INFO MEETW MEETU UNION LOGRY

\begin{tabular}{|c|c|c|c|c|c|c|c|}
\hline$\cdots$ & $\begin{array}{c}.001 \\
(.007)\end{array}$ & $\begin{array}{l}.015^{* * *} \\
(.005)\end{array}$ & $\begin{array}{c}.010^{*} \\
(.006)\end{array}$ & $\begin{array}{l}.012^{* * *} \\
(.004)\end{array}$ & $\begin{array}{l}.024^{* *} \\
(.012)\end{array}$ & ---- & $\begin{array}{l}.029 * * * \\
(.006)\end{array}$ \\
\hline
\end{tabular}


Notes to Table 5:

*** -- significant at .01-level

** -- significant at .05-level

* -- significant at .10-level

a -- Standard errors in parentheses

b -- Other control variables included in the OLS models are those listed in note $\mathrm{b}$ to Table 4 .

c -- Other control variables included in the OLS models are those listed in note $c$ to Table 4 . 
coefficients on the HRM System variables remain significant with precisely the same hierarchical pattern observed in Table 4. The coefficients on the individual variables for each HRM practice in line 2 of Panel Al are insignificant in all models except two (PROFIT SHARING and LOW TRAIN), where the effects are very modest.

The results from the fixed effects models are presented in Panel Bl of Table 5 and show the same pattern as the OLS results in Panel A $1 .{ }^{27}$ In models that include both HRM System variables and variables that measure individual HRM practices, the coefficients on the individual HRM practices are all virtually zero (line 2, panel B1). ${ }^{28}$

The models in Panels Al and B1 of Table 5 show that marginal changes in individual HRM practices have little or no impact on productivity, while changes in systems of HRM practices have much larger impacts on productivity. When lines add multiple practices and move to a new HRM System, their productivity increases, as indicated by the HRM System coefficients in the fixed effects model. But when lines change individual HRM practices without supporting changes in other related practices, productivity is unchanged.

To highlight the importance of including the HRM System variables in the productivity model, we also estimate uptime regressions that include the individual HRM variables, but omit the HRM System dummy variables. While almost all coefficients on the individual HRM practice variables in OLS models that included the HRM System dummies

\footnotetext{
${ }^{27}$ As in Table 4, the HRM System 1 variable could not be included in fixed effects models since no line switched into this category with the most innovative HRM practices. Also, some fixed effects models could not be estimated because certain individual HRM policies do not change in any lines in the sample period.

${ }^{28}$ The lone exception is in the fixed effects model which includes the Low Grievance variable. This variable, rather than the HRM Systems variables, is significant suggesting that productivity-enhancing changes in HRM Systems are consistently accompanied by a movement to an environment with little grievance activity.
} 
were not significantly different from zero (Panel A1, line 2), the coefficients on the individual practice variables are positive and significant with magnitudes ranging from about 1 to 3 percentage points in the models that omit the HRM System dummies (Panel A2, line 1). Similarly, in the fixed effects models that omit the HRM System dummy variables, eight of ten coefficients on the variables measuring individual HRM practices are significant (Panel B2, line 1), whereas only one coefficient was positive and significant in the corresponding models with the HRM System dummies (Panel B1, line 2) ${ }^{29}$ In both the OLS and fixed effects models, the apparent positive effects for many individual HRM practices (in Panels A2 and B2, omitting the system variables) become insignificant once the HRM System variables are also included (in Panels Al and Bl).

The full set of results in Table 5 show that it is not simply the case that implementing single HRM policies, like work teams, quality circles, job rotation, or information sharing, will improve productivity. Rather, the results in Panels Al and Bl of Table 5 show that there is a more complex dynamic behind the apparent positive effects of individual HRM practices shown in Panels A2 and B2 of Table 5. Specifically, in some lines, like the lines in HRM System 1, the individual HRM practices are part of a full system of innovative HRM practices. In these lines, workers have: skills and knowledge; effective group incentives; a norm of high effort and a culture of positive peer pressure due to careful selection, early indoctrination and team activities; and high levels of trust in management that make other HRM practices like employment security pledges credible and effective. In contrast, in other

\footnotetext{
${ }^{29}$ Fixed effects models which include the Multiple Teams (MTEAM) and Information Sharing (INFO) variables could be estimated in Panel B2 without the HRM system dummies because these variables do change over time within some lines. However, within-line changes in these two variables are collinear with switches between certain HRM Systems, and so the two corresponding fixed effects models in Panel B1 could not be estimated.
} 
lines where individual practices are not coupled with other complementary HRM practices, productivity is much lower. The coefficients on individual practices in models without controls for HRM systems reflect the combined effect of high productivity in a few lines that have the practice in conjunction with other complementary practices and much lower productivity for other lines that have the given practice but do not have the other complementary practices. ${ }^{30}$

As a second test of the hypothesis that HRM practices are complementary inputs into a firm's production function, we test whether the implicit interactions among HRM practices, as measured by the HRM System variables, are significant in models that also contain the full set of variables measuring individual HRM practices. In an OLS model corresponding to the Table 4, column 5 model, but which also includes all individual HRM policies, an F-test rejects the hypothesis that the HRM System variables add no explanatory power to the model which already includes all individual HRM policies entered separately $(F[3,2134]=7.62)$. Similarly, an F-test rejects the hypothesis that the HRM Systems variables add no explanatory power to a fixed effects model which already includes all individual HRM practices that change over time in the sample period $(F[2,2142]=5.40)$.

The results in Tables 2 and 3 on the distribution of HRM practices and in Tables 4 and 5 on the productivity effects of HRM practices tell a remarkably consistent story

\footnotetext{
${ }^{30}$ The estimated negative coefficient on union status in Panel A2 of Table 5 also reflects the more complex dynamics of how systems of HRM policies determine productivity. On average, union lines are less productive than nonunion lines in our sample. But, not all union lines are less productive than the nonunion lines in the sample. Lines in HRM System 1 are all unionized lines. The negative union coefficient in Panel A2 of Table 5 reflects the fact that a large number of union lines have the low productivity practices of HRM Systems 3 and 4 . It is also not simply the case that union lines are the only lines that can implement teams effectively or have effective voice mechanisms. The nonunion lines in this sample are all in HRM System 2. These nonunion lines showed extensive evidence of employee voice and participation, and were not characterized by the adversarial relations and the atmosphere of high grievances and poor communication observed in organized lines with HRM System 4.
} 
supporting the empirical hypotheses of Section I. Systems of HRM policies determine

productivity. Marginal changes in individual policies have little effect on productivity.

Improving productivity requires substantial changes in a set of HRM policies. Moreover,

those lines that have a combination of practices spanning all seven HRM policy areas have

the highest levels of productivity.

The Effects of HRM Systems on Quality of Production Output

One remaining reason why the estimates in Tables 4 and 5 may overstate the

performance effects of HRM systems is that the lines with more progressive HRM systems

that have higher levels of uptime, and thus output, may be producing lower quality steel. We

have also collected data to examine this possibility. Most lines that supplied us with uptime

data also supplied data on their monthly "prime yield" rates -- the percent of total production

that met the standards for designation as "prime" finished steel.

Table 6 presents estimates of the effects of HRM Systems on prime yield rates ${ }^{31}$ in

OLS and fixed effects models that also include the various detailed controls for steel input quality, capital vintage, machinery, scheduled maintenance and other controls included in the delays equations. ${ }^{32}$ The same hierarchical pattern observed in the delays models in Tables 4 and 5 tends to be in evidence again in the prime yield models in Table 6. Lines with HRM

\footnotetext{
${ }^{31}$ Because total steel production is the denominator of the prime yield rate variable, these estimates are not affected by any effects of the HRM System variables on production and line delays.

${ }^{32}$ The prime yield regressions include additional controls not included in the uptime regressions to account for slight differences in the way prime yield is measured from line to line. For example, prime steel production might be expressed as a percent of total tons of steel at the exit end of the finishing line or as a percent of total tons of steel input on the entry end of the line. To control for these small differences in the calculation of prime yield, we identified the precise definitions at each line and included five dummy variables for the five slightly different ways that prime yield was defined at different lines. These dummy variables in OLS specifications are consistently significant with the expected signs given the differences in the definitions. The definitions the lines used to calculate prime yield do not change over time, and so these variables drop out of the fixed effects models.
} 
TABLE 6

Estimated Effects of HRM Systems on Quality of Production in OLS and Fixed Effects Models

Dependent Variable: (\%Prime Yield)

$[N=1750]$

\begin{tabular}{|c|c|c|c|}
\hline & $\begin{array}{c}\text { OLS Models } \\
\text { Without Detailed } \\
\text { Machinery Controls }^{2}\end{array}$ & $\begin{array}{c}\text { OLS Models } \\
\text { With Detailed } \\
\text { Machinery Controls }\end{array}$ & $\begin{array}{l}\text { Fixed Effects } \\
\underline{\text { Models }}^{\varepsilon}\end{array}$ \\
\hline$\underline{\text { HRM Measure }}$ & (1) & (2) & (3) \\
\hline 1a. HRM System 1 & $\begin{array}{l}.152^{* * *} \\
(.008)\end{array}$ & $\begin{array}{l}.132^{* * *} \\
(.009)\end{array}$ & --- \\
\hline 1b. HRM System 2 & $\begin{array}{l}.098^{* * *} \\
(.005)\end{array}$ & $\begin{array}{l}.046^{* * *} \\
(.007)\end{array}$ & $\begin{array}{l}.036 * * * \\
(.007)\end{array}$ \\
\hline Ic. HRM System 3 & $\begin{array}{l}.064^{* * *} \\
(.004)\end{array}$ & $\begin{array}{l}.044^{* * *} \\
(.005)\end{array}$ & $\begin{array}{l}.050 * * * \\
(.005)\end{array}$ \\
\hline
\end{tabular}

\section{Notes to Table 6:}

a -- Control variables in column 1 are: number of years line has been operating and years squared; year line was built and year built squared; dummy for startup periods indicated by first twelve months of operations and 1-to-12 time trend for month of startup operation; 1-to-5 index of quality of steel input; number of annual 8-hour scheduled maintenance shifts; and five dummies for slight differences in how prime yield is measured in different lines.

b -- Control variables in column 2 are: all controls listed in note a; dummy for type of customer; maximum spced of line and speed squared; maximum width of the line and width squared; nine dummies to indicate specific pieces of equipment from start to finish of the line and a measure of the age of one piece of equipment at end of the line; a dummy to indicate high and low levels of computer control of line operations; and a variable to measure 6-month periods from the date that any new major pieces of equipment are introduced; and five dummies for slight differences in how prime yield is measured in different lines.

c -- Control variables in column 3 are: age of line and age squared; dummy for startup periods indicated by first twelvc months of operations and 1-to-12 time trend for month of startup operation; 1-to-5 index of quality of steel input; age of the end-of-the-line piece of equipment; a variable to measure 6-month periods from the date that any new major pieces of equipment are introduced; and estimated changes in the value of capital due to the introduction of any new major pieces of machinery from the date the new equipment was installed. 
System 1 have prime yield rates that considerably exceed the yields of lines with other HRM

Systems. HRM Systems 2 and 3 produce comparable gains in prime yield rates relative to

HRM System 4. Fixed effects results also demonstrate higher yield rates under more innovative HRM practices. ${ }^{33}$

Taken as a whole, the results in Tables 4 through 6 show dramatic effects of different HRM Systems. The differences in economic performance are especially striking between: (a) HRM System 1 where lines carefully select employees, provide extensive training in production skills and problem-solving techniques, have detailed production and pay-forknowledge incentives, have extensive labor-management communication, and encourage teamwork and worker participation, and (b) HRM System 4 where lines adopt traditional employment practices and maintain adversarial relations with their employees. These results imply that a more carefully crafted system of HRM policies makes it possible for employees in manufacturing establishments to produce significantly higher levels of high-quality output.

\section{WHY DONT ALL LINES HAVE THE HIGH PRODUCTIVITY HRM SYSTEMS?}

The econometric evidence in Section IV reveals productivity advantages of 6.7, 3.2, and 1.4 percentage points for finishing lines with HRM Systems 1, 2, and 3 respectively, compared to finishing lines with HRM System 4 (Table 4, column 5). Finishing lines with the more innovative HRM systems also produce a higher percentage of "prime quality" tons, further magnifying the performance differences due to HRM Systems.

\footnotetext{
${ }^{33}$ The OLS and fixed effects prime yield regressions were reestimated with corrections for first-order serial correlation. Standard errors in these models were only slightly larger than those in the Table 6 models. Magnitudes and levels of significance of HRM System coefficients are very similar to those reported in Table 6.
} 
Estimates of the Value of the Productivity Effects of HRM Systems

Productivity differences of this magnitude are economically important to these lines.

Based on detailed cost data from one small-scale line, a very conservative estimate of the impact of a one percent increase in uptime on operating income for this line is approximately $\$ 30,000$ per month. ${ }^{34}$ Using data from interviews and site visits, we also estimate that the costs directly associated with setting up and maintaining the new work practices that comprise the more productive HRM Systems is about $\$ 2,100$ per percentage point increase in uptime per month, implying a net gain of $\$ 27,900$ per month for each percentage point gain in uptime. $^{35}$ Furthermore, this estimate also understates the revenue effects of progressive HRM Systems because most finishing operations are of much larger scale and would tend to have bigger revenue effects from reducing delays and because the estimate does not include gains due to increased product quality.

To help visualize the gains from changing HRM systems, we present the data from one line in our sample that changed from HRM System 4 to HRM System 2 and experienced

\footnotetext{
${ }^{34}$ During a delay, a line loses revenue from planned output. It does not incur certain variable costs such as steel input costs and much of the energy costs. It still incurs other "variable" costs, such as labor costs which are typically paid during down time, and fixed costs. These fixed costs are significant, with hourly fixed cost charges exceeding $\$ 5000$ at some lines. The $\$ 30,000$ estimate of the impact of a one percent increase in uptime is based on a conservative estimate of the profit margin for a ton of steel and liberal estimates for the costs that would not be incurred during a delay.

${ }^{35}$ For these calculations, we estimate the difference in the costs of setting up and maintaining the work practices in HRM System 1 versus HRM System 4. The initial fixed costs are those associated with introducing teams, extra training, incentive pay, and job flexibility. The costs of maintaining these practices include the time production workers must meet off the line, hiring an additional HRM staff person, and hiring consultants for on-going training and team organization. We also add the cost of employment security for wages paid for idle time, assuming that the line would be idle for two months every four years. Finally, we subtract the cost of one foreman since the more innovative HRM Systems eliminate the need for approximately one foreman. Assuming a relatively short time horizon of five years for amortizing fixed costs, the annual difference in costs between HRM Systems 4 and 1 is about $\$ 25,000$ per percentage point gain in uptime. These costs will be smaller for large plants due to economies of scale in the implementation of new HRM practices
} 
large increases in uptime. Figure 1 plots unscheduled delays (i.e., (1-uptime)) for this line between 1983 and 1992. This line began changes in HRM practices in March 1983 to move from HRM System 4 to System 2. Line delays had consistently hovered around 12 percent prior to the HRM changes and declined to about 4 percent soon after the HRM changes. ${ }^{36}$ According to the estimates in Table 4, column 9, 3.5 percentage points of this eight percent improvement in uptime can be attributed to the new HRM practices themselves. ${ }^{37}$ Valuing each percentage point increase in uptime at $\$ 27,900$ implies a $\$ 97,650$ monthly increase in operating profits for this changed line, a $\$ 1,171,800$ annual increase in operating profits, and a $\$ 12,889,800$ increase (without discounting) over the eleven years that this line has been able to sustain the improved performance under the new HRM system. Even if this line operated $20 \%$ below capacity over this period, the change in operating income from a 3.5 percentage point increase in uptime over an eleven-year period would still exceed $\$ 10$ million. The fact that quality of production increased as well after changing HRM Systems only magnifies the difference in the value of employing more progressive HRM systems.

\footnotetext{
${ }^{36}$ The time series plot in Figure 1 shows that delays decline to about $4 \%$ a few months after March 1983 when large-scale changes in HRM practices occurred, suggesting that there may be a lag in the effect of new HRM practices on productivity. We find evidence of a very modest three month lag in the OLS and fixed effects uptime models. For example, when the fixed effects uptime regression (column 9, Table 4) is reestimated with a lag of three months introduced in the HRM System variables, their coefficients rise by about .005 (e.g., from .025 to .030 for HRM System 3). These lagged HRM variables provide a slightly better description of the changes in productivity due to new HRM practices than do the concurrent values of the HRM Systems. In the fixed effects model, an F-test reveals that the 3-month lags in HRM System 2 and System 3 add explanatory power to the uptime model already containing the concurrent HRM System variables $(F(2,2065)=3.64)$, whereas the converse test concerning the addition of concurrent HRM System variables to a model that has the lagged HRM variables is insignificant $(F(2,2065)=1.17$. We found no evidence of productivity effects of leads in HRM systems, and no evidence of declining productivity just before the introduction of new HRM systems.

${ }^{37}$ Much of the rest of the 8 percentage point improvement in this line's uptime in early 1983 is attributable to the fact that this line began to use higher quality steel input from a new supplier near the time of the HRM changes. Estimates from the fixed effects model (Table 4, column 9) show that increases in steel input quality improves uptime.
} 


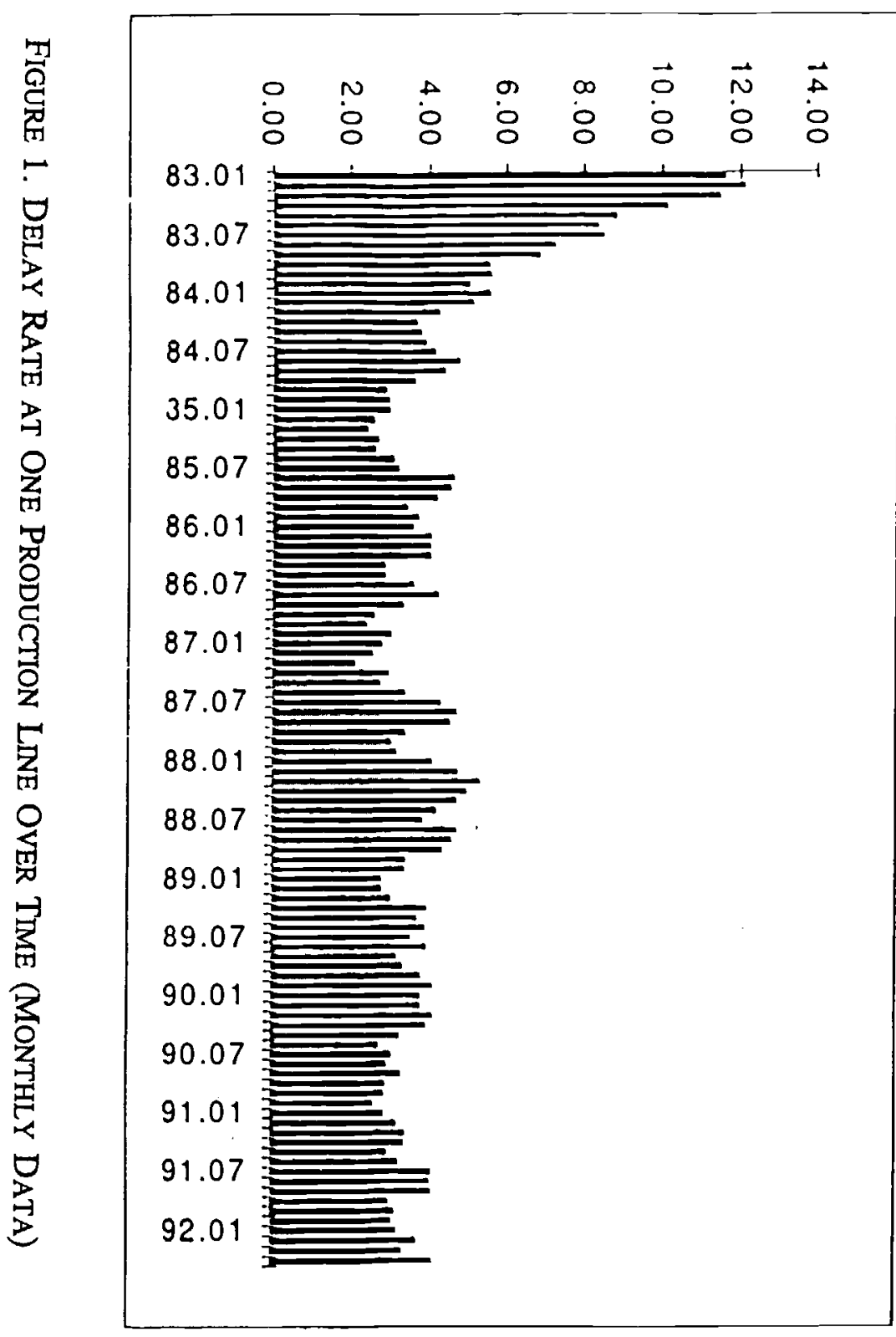


Assessing Potential Sources of Bias in the Estimated Performance Effects of HRM Systems

If the more progressive HRM systems promote economic performance to this extent, why don't all lines adopt them? One possible answer is that the estimated coefficients on the HRM System variables may be biased upward, implying that the actual effects of the HRM Systems smaller than those shown in Tables 4-6.

Estimated productivity effects of HRM Systems are biased if the error term in the productivity equation is correlated with HRM System choice. The notion that factors like better unmeasured capital equipment or a better-educated workforce could make the more progressive HRM systems a more appropriate choice for certain lines may still be reasonable, despite the careful specifications of control variables and the homogeneity of the sample, if the omission of such factors introduces a bias in the OLS specification. But the possibility of bias in the estimated productivity effects of HRM Systems must also be assessed in the context of the fixed effects models. According to the within-line estimates of the fixed effects model, productivity increases are observed with exactly the same equipment and same workers after lines adopt more progressive HRM systems.

In particular, in the equation (5) fixed effects model [i.e., $\left(1-d_{i t}\right)=\alpha_{i}+\beta^{\prime} X_{i t}+$ $\gamma^{\prime} \mathrm{HRM}_{\mathrm{it}}+\varepsilon_{\mathrm{it}}$ ], $\gamma^{\prime}$ is identified from the productivity outcomes of "HRM changers." This coefficient will be biased if $\varepsilon_{i t}$ is correlated with changers' HRM system choice. For example, endogeneity bias affects $\gamma^{\prime}$ only if within-line changes in productivity over time cause changes in HRM practices. Similarly, sample selection bias affects $\gamma^{\prime}$ only if the subsample of "changers" differs from the subsample of "non-changers" in a way that is correlated with the expected productivity gains to HRM innovations. 
Based on our on-site investigations of these finishing lines, we believe that these potential sources of bias in the fixed effects results are negligible. In particular, the technology of the production lines and the quality of the workforces are virtually identical for the older lines that did and did not change HRM practices. We therefore expect that productivity gains of adopting new HRM systems would be similar for the non-changers and changers.

It also seems very unlikely that the coefficients on HRM System variables are biased upward in other ways by the effects of omitted variables. First, the nature of the sample design and data collection process make this an unlikely possibility. The data set by its very design eliminates issues of unobserved heterogeneity due to sector, industry, and production technology. The specifications of control variables in the productivity model were developed only after we had conducted on-site inspections of all production lines. Moreover, omitted variables, such as better unmeasured capital equipment or higher quality workers, are not a source bias in the estimates from the fixed effects models. Any factors that changed near the time of changes in HRM practices which might possibly be responsible for productivity changes were carefully identified during on-site investigations with senior managers and employees, and data on these potential determinants of productivity are included in the productivity models. ${ }^{38}$

\footnotetext{
${ }^{38}$ For example, managers at the line shown in Figure 1 attested to the importance of the new HRM environment in improving productivity, but warned us against attributing the full reduction in delays to the HRM systems since the line began to receive better quality steel input near the time of the HRM change. We collected data on steel input quality and found significant coefficients on both the HRM Systems variables and on the variable measuring the quality of the steel input in the fixed effects models. The result that HRM systems have large significant effects on productivity in the fixed effects model is robust with respect to inclusion of these controls and with respect to other sensitivity tests. As described in note 23 supra, we also investigated the effects of more complex learning curve effects, changes in management, and other factors which proved to have no significant productivity effects.
} 
One final variable that is omitted from the productivity models that could possibly explain variations in productivity is wages. The question is, are workers in HRM System 1 lines working harder because they are paid more? To test this possibility directly, we collected wage data from company records or used the most recent union contracts (1989 to 1993 ) coupled with interview information to estimate average wages. ${ }^{39}$ When we include observations on wage rates, our sample size falls to 863 due to the focus on the recent time period. The uptime model is reestimated for this sample with and without the average wage of production workers. The coefficient on the average wage is insignificant in all OLS and fixed effects models, thus there are no changes in the coefficients on the HRM variables when the wage variable is introduced. ${ }^{40}$ Wages are determined by factors that are exogeneous to the current performance of the particular production line we study. ${ }^{41}$

\footnotetext{
${ }^{39}$ When provided by the company, the average wage data is the average wage for production workers, including incentive pay, overtime pay, shift pay, and profit sharing. When these averages are not available for the production line, we use the union labor contracts to predict average wages, combined with interview information on the average grade level, average amount of overtime, and average incentive pay percentages (including profit sharing). Only two lines were unable to provide data for the calculation of average wages. Fringe benefit compensation is omitted, and though it is slightly higher in unionized lines than nonunion (due to higher pensions and days off), it does not change with the "HRM changers" timing. In addition, the conclusion that wages are not significant determinants of uptime persists when the sample for the uptime regressions is restricted to unionized lines.

${ }^{10}$ The coefficients (standard errors) on the wage variable are $.00016(.00079)$ for the OLS model with detailed controls and $.00168(.00172)$ for the fixed effects model. The coefficients on the HRM variables for the subsample having wage data $(\mathrm{N}=863)$ are slightly smaller in magnitude than in the full sample, but remain significantly different from zero. These results are unchanged when real wages replace nominal wages.

1 The insignificance of the wage variables is consistent with the interview evidence that we gathered and with the known pattern of wage changes over time. Wage changes are generally the result of contractual changes negotiated in national contracts, so they are not correlated with line-level changes in HRM choices and do not affect fixed effects uptime regression results. Regarding our interview evidence, nonunion lines state that they intentionally offer wages that are comparable to unionized lines, and unionized lines have pay packages that are quite similar to one another. As a result, average wages are quite homogeneous across lines: the average nominal wage for the sample is $\$ 17.67$ with a standard deviation of only $\$ 2.65$. Interview evidence suggests that wages are also very homogeneous within lines.
} 


\section{Differences in the Costs and Profitability of Adopting New HRM Systems}

Given the nature of the sample, the careful specification of the control variables in the productivity model, the corroborating evidence in the fixed effects models, and the personal knowledge of the details of each production site gained from on-site interviews, an argument that the estimates of the productivity effects of HRM systems are biased upward does not seem very compelling. What then explains the limited adoption of the most productive HRM Systems?

The critical differences across lines and within lines over time that explain why some lines do not adopt the most productive HRM systems seem to lie in differences in the expected profitability of the HRM systems. The expected profitability of adopting HRM practices will vary across observations in this sample for reasons other than the size of the productivity increases due to HRM practices. While a full exploration of factors which determine the profitability of adopting HRM practices is beyond the scope of the data available for this study, our field investigations provide evidence on this issue.

In particular, it is principally older lines that operate under the less productive HRM Systems 3 and 4, since older lines adopted more traditional work practices before manufacturing firms had much experience with the newer approaches to work organization. In these older lines, with their long histories of adversarial relations under more traditional work practices, workers and supervisors provide stiff resistance to any new work practices. For older lines considering new work practices, this employee resistance to new work practices amounts to a switching cost that is greater than the direct costs of introducing the practices and that new lines do not face when they are setting up their initial sets of work 
practices. $^{42}$

One particularly important source of these switching costs and employee resistance to new work practices in older lines is a low level of trust between labor and management in older lines. Baker, Gibbons, and Murphy (1993) show how trust is needed for many innovative HRM practices to work, and our interviews revealed how a low level of labormanagement trust in older lines rendered work practices like information sharing, ${ }^{43}$ productivity-improvement teams, ${ }^{44}$ and employment security ${ }^{45}$ ineffective. New lines without this history of mistrust therefore have a decided advantage in implementing new HRM systems, ${ }^{46}$ because these lines do not have to incur the costs of overcoming long histories of mistrust between labor and management to make new HRM practices credible and effective.

Our field investigations of older lines also helped identify specific factors which changed over time in some older lines and reduced the costs of adopting new HRM practices.

\footnotetext{
${ }^{42}$ At the same time, the older technology of these lines is not itself responsible for the limited adoption of new work practices. Detailed controls in the productivity models for capital vintage do not eliminate the productivity effects of HRM Systems for several reasons. When older lines in the sample were shut down and later reopened by new owners, all adopted many new work practices. And, as illustrated by the results of the fixed effects models, some continuously operating older lines adopted new HRM Systems which raised their productivity.

${ }^{43}$ The manager at one older line that instituted a policy of sharing financial data with workers observed "It's just difficult to change attitudes in old plants with a history of tension and mistrust. We now share financial information with workers, but some workers still believe there are two sets of books."

${ }^{44}$ A manager at another old line with adversarial labor-management relations where productivity-improvement teams had been instituted noted that "Workers and union leaders thought the Labor-Management Participation Teams [LMPT's] were just another trick by management to cut jobs. Workers called LMPT's 'Less Manhours Per Ton.'"

${ }^{45}$ A supervisor who managed an older line subject to a labor contract that promised employment security to all non-probationary workers noted that "Workers out here don't believe they have employment security. They know the contract is going to be renegotiated next spring. Since employment security is only a contractual guarantee, they know it may very well go away in the next contract."

46 A manager at a startup finishing line noted the importance of labor-management trust for achieving high worker productivity: "If I had been a supervisor from [the employees' previous steel mill], the workers would have the whole book on me. They'd know what kind of SOB I was. You can't generate trust starting with those beliefs."
} 
In particular, "HRM System changers" are more likely to be lines threatened by plant closure in the near term. Furthermore, as a result of actual shutdowns of production capacity at the same mill or a nearby mill, this threat became credible to workers who otherwise would mistrust managers' claims that the line is facing hard times. This credible threat of plant closure significantly lowers the costs of transition to new HRM practices by weakening the resistance of managers and workers to these changes. At the same time, the evidence indicates that the threat of plant closure is not an omitted variable that is the real cause of the productivity increases. ${ }^{47}$

In sum, employee resistance to new work practices and low labor-management trust create substantial switching costs in older lines. It is the variation in these costs across lines and within lines over time that allow us to observe different work practices within this technologically homogeneous sample. Under some circumstances, these switching costs and the attendant employee resistance to new practices will be reduced in older lines. In these cases, when older lines do adopt new practices, productivity improves as shown in the fixed effects models.

\section{CONCLUSION}

This paper presents new evidence on the productivity effects of employment practices, practices such as incentive pay schemes, the use of work teams, and enhanced training for

\footnotetext{
${ }^{47}$ We constructed a variable representing the percent of the plant that is shutdown and entered this in the uptime regression (about 23 percent of the lines had some portion of their line shut down). It is insignificant. There are several reasons why the threat of plant closure does not account for the estimated effects of HRM practices on productivity. First, not all threatened lines changed their HRM practices. Second, the threat alone does not enable workers to become more productive or to generate the kinds of productivity-enhancing ideas observed after new HRM practices are adopted. Workers need more training, information, skills for team problem-solving processes, and other benefits of the new HRM practices. Third, lines that have changed their HRM practices have sustained increases in uptime after the threat of closure has dissipated. Fourth, innovative HRM practices are adopted widely by new lines that have no threat of closure, and the practices are associated with success in these lines as well.
} 
production workers. The principal finding is that systems of complementary HRM practices have large effects on production workers' performance, while changes in individual employment practices have little or no effect. The evidence, derived from unique monthly panel data on productivity and HRM practices in a homogeneous sample of production lines, supports recent theoretical work on incentive contracts that emphasizes the importance of sets of complementary employment practices for developing the most effective incentive structures. The evidence also supports the theoretical arguments that incentive pay plans and their related supporting practices raise worker performance, relative to the effects of more traditional practices in manufacturing, such as fixed hourly pay. 


\section{BIBLIOGRAPHY}

Alchian, A. and Harold Demsetz, "Production, Information Costs, and Economic Organization," American Economic Review, September 1972, 62(4), pp. 777-795.

Aoki, Masahiko. Information, Incentives and Bargaining in the Japanese Economy. New York: Cambridge University Press, 1988.

Baker, George, Gibbons, Robert, and Murphy, Kevin J. "Subjective Performance Measures in Optimal Incentive Contracts." Quarterly Joumal of Economics, November 1994, 108(8), pp. 1125 56.

Belsley, D.A., Kuh, E., and Welsch, R. Regression Diagnostics. New York: John Wiley and Sons, 1980.

Carmichael, H. Lorne, and MacLeod, W. Bentley. "Multiskilling, Technical Change, and the Japanese Firm." The Economic Joumal, January 1993, 103(416), pp. 142-160.

Farrell, Joseph, and Robert Gibbons, "Bargaining Power and Voice in Organizations," manuscript, March 1991.

Freeman, Richard B., "The Exit-Voice Tradeoff in the Labor Market: Unionism, Job Tenure, Quits, and Separations," Quarterly Joumal of Economics, June 1980, 94 (4), pp. 643-674.

Ghiselli, Edwin, Campbell, J.P., and Zedeck, S. Measurement Theory for the Behavional Sciences. San Francisco: Freeman and Sons, 1981.

Hart, Oliver. "Optimal Labor Contracts Under Assymmetric Information," Review of Economic Studies, January 1983, 50(160), pp. 3-35.

Hirschman, Albert O. Exit, Voice, and Loyalty. Cambridge, Mass.: Harvard University Press, 1979.

Holmstrom, Bengt. "Moral Hazard in Teams." Bell Joumal of Economics, Autumn 1982, 13(2), pp.324-40.

Holmstrom, Bengt, and Milgrom, Paul. "The Firm as an Incentive System." American Economic Review, September 1994, 84(4), pp.972-91.

Ichniowski, Casey. "The Effects of Grievance Activity on Productivity." Industrial and Labor Relations Review, October 1986, 40(1), pp. 75-89.

Jensen, Michael C. and Kevin J. Murphy, "Performance Pay and Top-Management Incentives." Joumal of Political Economy, April 1990, 98(2), pp. 225-264. 
Kandel, Eugene, and Edward Lazear. "Peer Pressure and Partnerships." Joumal of Political Economy, August 1992, 100(4), pp. 801-17.

Lazear, Edward. "Salaries and Piece Rates." Joumal of Business, July 1986, 59(3), pp.405-31.

Lazear, Edward. "Pay Equality and Industrial Politics." Joumal of Political Economy, August $1989,97(3)$, pp. 561-80.

Lazear, Edward. "Labor Economics and the Psychology of Organizations." Joumal of Economic Perspectives, Spring 1991, 5(2), pp. 89-110.

Lazear, Edward. "Compensation, Productivity and the New Economics of Personnel." in Research Frontiers in Industrial Relations and Human Resounces, eds. D. Lewin, O. Mitchell, and P. Sherer. Madison, Wisc.: IRRA, 1992.

Lazear, Edward and Rosen, Sherwin. "Rank-Order Tournaments as Optimum Labor Contracts." Joumal of Political Economy, October 1981, 89(5), pp. 841-64.

McAfee, Preston and John McMillan. "Optimal Contracts for Teams," Intemational Economic Review, August 1991, 32(3), pp. 561-577.

Milgrom, Paul and Roberts, John. "The Economics of Modern Manufacturing." American Economic Review, June 1990, 80(3), pp. 511-28.

Milgrom, Paul and Roberts, John. "Complementarities and Fit: Strategy, Structure and Organizational Change." manuscript, 1993.

Poole, Keith, and Rosenthal, Howard. "A Scaling Algorithm to Study Congressional Voting Behavior." manuscript, 1985.

Poole, Keith, and Rosenthal, Howard. "Patterns of Congressional Voting." American Joumal of Political Science, February 1991, 35(1), pp. 228-278.

Shapiro, Carl, and Joseph E. Stiglitz, "Equilibrium Unemployment as a Worker Discipline Device," American Economic Review, June 1984, 74(3), pp. 433-444.

Waldman, Michael, "Job Assignments, Signalling, and Efficiency," Review of Economic Studies, Summer 1984, 15(2), pp. 255-267.

Weiss, Andrew, "Job Queues and Layoffs in Labor Markets with Flexible Wages," Joumal of Political Economy, June 1980, 88(3), pp. 526-538.

Weitzman, Martin L., "Efficient Incentive Contracts," Quarterly Joumal of Economics, June 1980, 94(4), pp. 719-730. 
Weitzman, Martin L., and Douglas L. Kruse (1990) "Profit Sharing and Productivity," In Paying for Productivity: A Look at the Evidence, ed. Alan S. Blinder (Washington D.C.: The Brookings Institution), pp. 95-139. 
Appendix A

Full Set of Coefficient Estimates from Table 4, Column 5 OLS Uptime Model

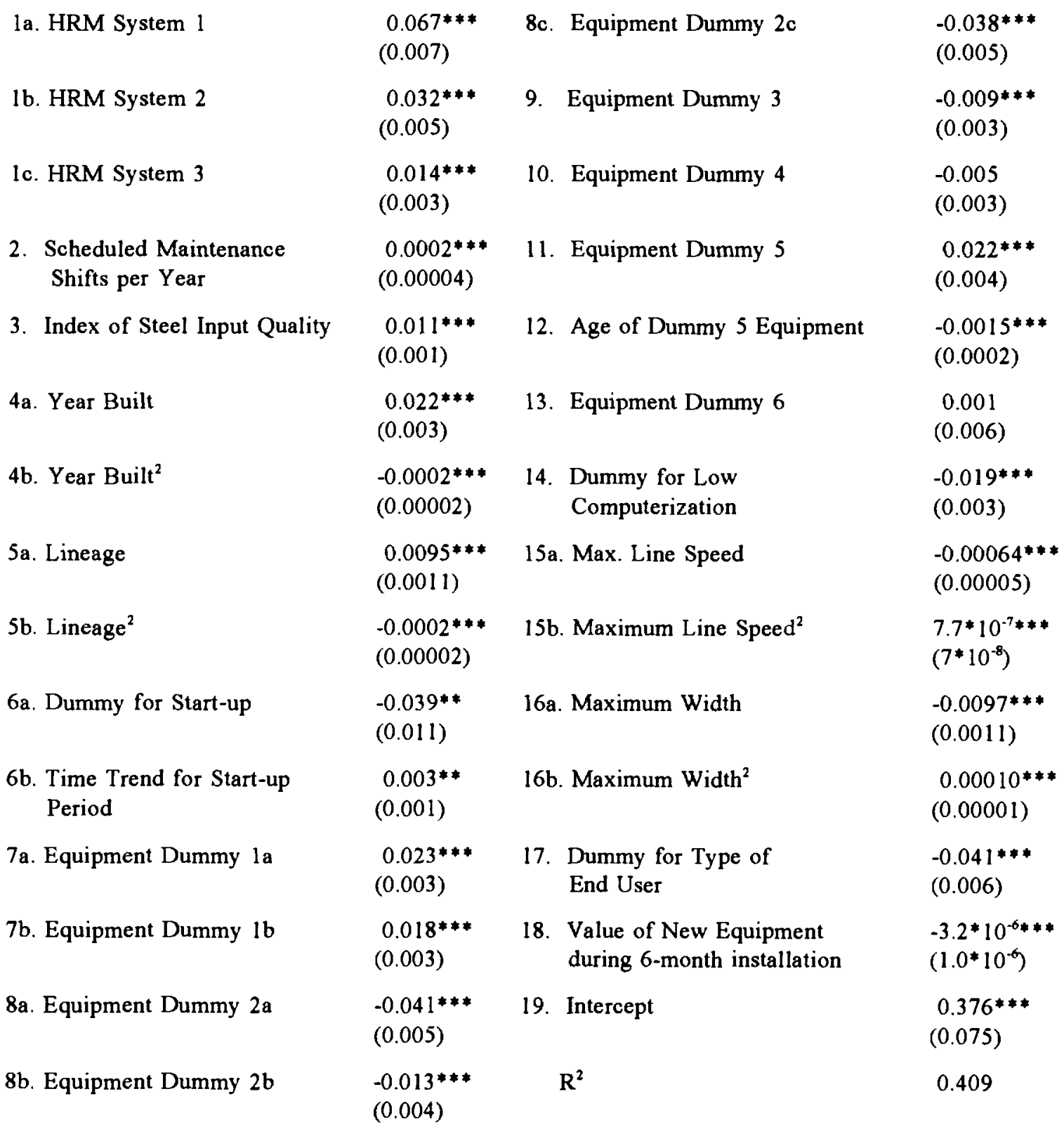

*** Significant at the .01 level.

** Significant at the .05 level.

* Significant at the .10 level. 